\title{
Connaissances nouvelles sur les propriétés fonctionnelles des protéines du lait et des dérivés
}

\author{
D Lorient, B Closs, JL Courthaudon \\ ENSBANA, Campus Universitaire, département de biochimie et toxicologie alimentaires, \\ 21000 Dijon, France
}

\begin{abstract}
Résumé - Grâce à une connaissance précise de leurs structures primaire et tridimensionnelle, on sait mieux comprendre les propriétés fonctionnelles des 5 protéines majeures du lait (caséines $\alpha_{s 1}$, $\beta$ et $\kappa, \beta$-lactoglobuline et $\alpha$-lactalbumine) et mieux les utiliser dans des produits carnés, des pâtisseries, des sauces et crèmes glacées.

On a pu ainsi relier aux propriétés de surface, des propriétés dynamiques telles que la flexibilité, ou hydrodynamiques telles que la viscosité intrinsèque. En mélange, des interactions s'établissent entre protéines et molécules protéiques ou non protéiques qui modifient le comportement fonctionnel des protéines du lait, ce qui permet d'expliquer :

- l'amélioration des propriétés tensioactives par purification : caséine $\beta>$ caséine $\alpha_{s 1}=$ caséine $\kappa>$ caséine entière, $\beta$-lactoglobuline $>\alpha$-lactalbumine $>$ lactosérum;

- l'amélioration du pouvoir gélifiant des carraghénanes par la caséine $\kappa$ (laits gélifiés);

- l'effet des surfactants sur les propriétés tensioactives des protéines dans les émulsions foisonnées (crèmes, glaces).

Les propriétés fonctionnelles du lactosérum peuvent être améliorées en modifiant le milieu (électrodialyse, ultrafiltration, échange d'ions), en dénaturant par voie thermique à pH neutre ou acide, en batch ou par des traitements en continu (échangeurs à surface raclée, cuisson-extrusion).

Les traitements chimiques restent des méthodes de laboratoire utilisées pour expliquer les relations structure-fonction. Quant à la protéolyse, elle ne peut s'appliquer que pour améliorer la solubilité.
\end{abstract}

propriété fonctionnelle / protéine / lait / lactosérum / gel / émulsion / mousse

Summary - Recent knowledge on the functional properties of milk proteins and related products. A study of the physico-chemical and functional properties of milk proteins in isolation is more straightforward than in complex food systems such as meat, baked products, sauces or ice cream. Caseinates are used for their binding and emulsifying properties, whilst whey proteins are mostly used for their gelling and foaming properties. A knowledge of the primary and 3-dimensional structures of the 5 main milk proteins ( $\alpha_{s,}, \beta$-, and $\kappa$-caseins, $\beta$-lactoglobulin and $\alpha$-lactalbumin), enables a better understanding of the functional behaviour of pure components on their own or in mixtures. Surface properties may be related to dynamic or hydrodynamic behaviour such as flexibility or intrinsic viscosity. These in turn depend on the extent of unfolding. Surface-acting properties are enhanced by $\beta$-casein, an amphipathic molecule which is naturally unfolded at $\mathrm{pH} 7$, while a rigid 3dimensional structure is required for $\beta$-lactoglobulin to stabilise emulsions and foams. The behaviour of milk proteins is changed when they are mixed with other protein or non-protein molecules (polysaccharides, lipids, surfactants). Different interactions occur, altering the behaviour of milk proteins by competition or synergistic effects. In the present study, the following situations are considered:

- the surface-active properties of pure proteins in the following order: $\beta$-casein $>\alpha_{s 1}$ casein $=\kappa$ casein > whole caseinate, $\beta$-lactoglobulin > $\alpha$-lactalbumin > whey;

- the improvement in the gelling capacity of carrageenans and galactomannans by the presence of $\kappa$-casein;

- protein-lipid interactions in emulsions;

- competition at the milk protein-surfactant interface. 
The following techniques, which have been used for some time to improve the functional properties of milk proteins, are also considered:

- changing the medium (electrodialysis, ultrafiltration);

- denaturing whey proteins (thermal denaturation at acidic or neutral $\mathrm{pH}$ or at the isoelectric point). Recent developments include the adaptation of continuous processes such as thermal denaturation and expansion in scraped surface heat exchangers or thermoplastic texturisation by cooker-extruder. Chemical modification of proteins is still utilised for the elucidation of structure-function relations. Proteolysis is only used in the improvement of whey protein concentrate solubility. These advances should facilitate the development of new products such as cheese or fat analogues by improving texture compatibility between different protein and non-protein components.

\section{functional property / protein / milk / whey / gel / emulsions / foam}

\section{INTRODUCTION}

Les protéines du lait sont de plus en plus utilisées comme ingrédients de texture dans de nombreux aliments intermédiaires ou prêts à être consommés. On connaît assez bien le comportement fonctionnel et individuel des caséinates et des concentrés protéiques de lactosérum en solution aqueuse et de nombreuses revues ont déjà établi l'inventaire des propriétés d'hydradation, de texture et de surface (Cheftel et Lorient, 1982; Fox et Mulvihill, 1983; Kinsella, 1984; de Wit, 1984; Kinsella et Fox, 1985; Modler, 1985; Anderson et al, 1987; Colas, 1988; Dumay, 1988; Leman et Kinsella, 1989). L'abondance des références bibliographiques dans ce domaine s'explique en grande partie par le fait que les structures primaires et tridimensionnelles des 6 protéines majeures du lait (caséines $\alpha_{\mathrm{s} 1}, \alpha_{\mathrm{s} 2}, \beta$ et $\kappa, \beta$-lactoglobuline et $\alpha$-lactalbumine) sont connues. II devient ainsi plus aisé de relier cette structure au comportement physico-chimique et fonctionnel et de prédire les propriétés d'un ingrédient dans un aliment déterminé en fonction des conditions de préparation. Cependant, la formulation des aliments d'aujourd'hui (produits carnés et de pâtisseries, sauces, desserts, laits fermentés, crèmes glacées) intègre des agents de texture mixtes, spécifiques à une utilisation et dont la composition résulte d'observations empiriques et d'un savoir-faire de spécialistes des mélanges; il devient impérieux de comprendre le comportement des molécules en mélanges par l'étude de leurs interactions entre elles et avec les constituants protéiques ou non protéiques naturellement présents dans les matières premières.

Après une revue des principales propriétés fonctionnelles des protéines du lait et des facteurs les influençant, seront évoqués les travaux les plus récents portant sur les interactions entre protéines (laitières et non laitières) et entre protéines et molécules non protéiques (polysaccharides tensioactifs, lipides). Enfin, il sera abordé l'amélioration des propriétés fonctionnelles par les traitements physiques et chimiques.

\section{PRINCIPALES PROPRIÉTÉS FONCTIONNELLES DES PROTÉINES DU LAIT}

Le comportement fonctionnel des protéines du lait (tableau I) dépend en grande partie de :

- leur comportement vis-à-vis de l'eau en relation avec leur structure spatiale et leurs propriétés physico-chimiques (voluminosité, hydrophobicité de surface, amphipolarité);

- leur flexibilité en relation avec la structure spatiale et la teneur en eau. 


\section{Relation entre structure spatiale et comportement vis-à-vis de l'eau}

\section{Les caséines}

Associées en micelles dans le lait, elles sont en solutions très stables à la chaleur, mais en revanche, très sensibles au $\mathrm{pH}$ et aux sels di- ou polyvalents. La surface de la micelle est très hydrophile, en raison d'une grande richesse de la périphérie en caséine $\kappa$; cela lui confère des propriétés d'hydratation exceptionnelles ainsi qu'une excellente aptitude à la fixation sur la membrane des globules gras du lait. C'est aussi cette structure qui explique sa coagulation enzymatique par la chymosine puisque la perte de glycomacropeptide, groupement glycosylé très polaire et situé en surface, provoque l'augmentation de l'hydrophobicité de surface et la coagulation.

Sous forme de caséinates alcalins, sans la présence de cations divalents, les monomères de caséine $\alpha_{s 1}, \alpha_{s 2}, \beta$ et $\kappa$, peuvent s'associer en pseudo-micelles volumineuses (Payens, 1982). N'ayant pas de structure tridimensionnelle stabilisée par des ponts disulfure, les caséines $\alpha_{s 1}$, et $\beta$ ont une structure très dépendante du $\mathrm{pH}$ et de la présence de cations divalents; en milieu neutre et alcalin, leur voluminosité s'accroît considérablement et les associations disparaissent (tableau II). Ceci se traduit par des propriétés exceptionnelles de viscosité et de surface. Les monomères très flexibles peuvent s'adsorber facilement aux interfaces eau/air (mousse) ou eau/huile (émulsion) et offrent aussi de nombreux sites polaires hydratables et

Tableau I. Principales propriétés fonctionnelles des protéines du lait. Main functional properties of milk proteins.

\begin{tabular}{|c|c|c|}
\hline Propriétés & Caséines & Protéines du lactosérum \\
\hline Solubilité & Insolubles à pH 4,6 & $\begin{array}{l}\text { Très solubles à tous les } \mathrm{pH} \text { Insolubles } \\
\text { à } \mathrm{pH} 5 \text { si thermodénaturées }\end{array}$ \\
\hline Viscosité & $\begin{array}{l}\text { Solutions très visqueuses à pH } \\
\text { neutre et alcalin Viscosité minimale } \\
\text { au } \mathrm{pHi}(4,6)\end{array}$ & $\begin{array}{l}\text { Solutions peu visqueuses sauf si ther- } \\
\text { modénaturées }\end{array}$ \\
\hline Hydratation & $\begin{array}{l}\text { Rétention d'eau élevée avec for- } \\
\text { mation de colle à forte concentration } \\
\text { Minimum au pHi }\end{array}$ & $\begin{array}{l}\text { Rétention d'eau s'accroissant avec la } \\
\text { dénaturation }\end{array}$ \\
\hline Gélification & $\begin{array}{l}\text { Pas de gélification thermique sauf } \\
\text { en présence de calcium. Gélification } \\
\text { de la micelle par la chymosine }\end{array}$ & $\begin{array}{l}\text { Thermogélification à partir de } 70^{\circ} \mathrm{C} \text { : } \\
\text { influence du pH et des sels }\end{array}$ \\
\hline $\begin{array}{l}\text { Propriétés } \\
\text { émulsifiantes }\end{array}$ & $\begin{array}{l}\text { Excellentes propriétés émulsifiantes } \\
\text { surtout à pH neutre et alcalin }\end{array}$ & $\begin{array}{l}\text { Bonnes propriétés émulsifiantes sauf } \\
\text { à } \mathrm{pH} 4 \text { à } 5 \text { si thermodénaturation }\end{array}$ \\
\hline $\begin{array}{l}\text { Propriétés } \\
\text { moussantes }\end{array}$ & $\begin{array}{l}\text { Bon foisonnement mais faible stabi- } \\
\text { lité des mousses } \kappa>\beta>\alpha_{s 1}\end{array}$ & $\begin{array}{l}\text { Bon foisonnement et excellente stabili- } \\
\text { lité des mousses } \beta \mathrm{Lg}>\alpha \mathrm{La}\end{array}$ \\
\hline $\begin{array}{l}\text { Rétention } \\
\text { d'arômes }\end{array}$ & Bonne rétention & $\begin{array}{l}\text { Rétention très variable avec l'état de } \\
\text { dénaturation }\end{array}$ \\
\hline
\end{tabular}


apolaires hydrophobes, sauf à proximité du $\mathrm{pH} 4,6$ pour lequel les caséines précipitent. En général, l'ordre d'efficacité décroissante de la tensioactivité suit celui de l'état de plus en plus structuré : caséine $\beta$ $>$ caséine $\alpha_{\mathrm{s} 1}$, > caséine $\kappa$. On attribue aussi ces excellentes propriétés de surface à l'amphipolarité des 2 constituants majeurs $\alpha_{s 1}$ et $\beta$; en effet, Lee et al (1987) montrent que la caséine $\beta$ perd ses propriétés de surface par élimination enzymatique des parties C terminales (193-209) très hydrophobes et $\mathrm{N}$ terminales (1-25) très hydrophiles. Shimizu et al (1983) avaient aussi observé pour la caséine $\alpha_{\mathrm{s} 1}$ que l'élimination enzymatique des régions $\mathrm{N}$ terminales (1-40) hydrophiles et $\mathrm{C}$ terminales (134-199) hydrophobes altérait les propriétés tensioactives. De plus, on constate sur la figure 1 que les protéines globulaires telles que $\beta$-lactoglobuline s'adsorbent moins rapidement aux interfaces. Certains auteurs tels que Nakai (1983), Townsend et Nakai (1983) ont essayé de corréler l'hydrophobicité aux propriétés de surface; il semble que l'hydrophobicité de surface soit corrélée aux propriétés émulsifiantes alors que l'hydrophobicité moyenne le serait plutôt aux propriétés moussantes. On explique cela par le fait que la tension interfaciale entre l'eau et l'huile est plus faible que la tension superficielle entre l'eau et l'air; dans une mousse, les molécules sont plus déplissées et ce sont bien tous les tronçons hydrophobes de la molécules qui sont susceptibles d'être adsorbés. Les caséines étant toujours très déplissées aux interfaces, sont toutes très tensioactives en raison de leur forte hydrophobicité moyenne (surtout la caséine $\beta$ ).

\section{Les protéines du lactosérum}

Beaucoup plus structurées par leurs ponts disulfures, la $\beta$-lactoglobuline et l' $\alpha$ lactalbumine sont des protéines globulaires dont la structure spatiale est peu influencée par le $\mathrm{pH}$ et les sels. Même si elles ont une hydrophobicité moyenne éle-

Tableau II. Viscosités intrinsèques des caséines. Intrinsic viscosity of caseins.

\begin{tabular}{|c|c|c|}
\hline Caséines & Viscosité intrinsèque $\mathrm{ml} / \mathrm{g}$ & Conditions \\
\hline$\alpha_{\mathrm{s} 1}$ & $\begin{array}{c}10,2 \\
11,8 \\
7,7 \\
9,3 \\
19 \\
19,2\end{array}$ & $\begin{array}{l}0,01 \mathrm{~mol} . \mathrm{I}^{-1} \mathrm{KCl}, \mathrm{pH} 7,37^{\circ} \mathrm{C} \\
0,01 \mathrm{~mol} . \mathrm{I}^{-1} \mathrm{KCl}, \mathrm{pH} 7,4^{\circ} \mathrm{C} \\
0,1 \mathrm{~mol} . \mathrm{I}^{-1} \mathrm{KCl}, \mathrm{pH} 7,20^{\circ} \mathrm{C} \\
0,1 \mathrm{~mol} . \mathrm{I}^{-1} \mathrm{KCl}, \mathrm{pH} 7,4^{\circ} \mathrm{C} \\
0,1 \mathrm{~mol} . \mathrm{I}^{-1} \mathrm{KCl}, \mathrm{pH} 7 \\
6 \mathrm{~mol} .1^{-1} \mathrm{Gu} \mathrm{HCl}, 20^{\circ} \mathrm{C} \\
\mathrm{pH} 12,25^{\circ} \mathrm{C}\end{array}$ \\
\hline$\alpha_{s 1}$ & 11,3 & $0,1 \mathrm{~mol} . \mathrm{I}^{-1} \mathrm{NaCl}, \mathrm{pH} 7$ \\
\hline$\beta$ & $\begin{array}{l}23 \\
22,2\end{array}$ & $\begin{array}{l}\mathrm{I}=0,2, \mathrm{pH} 7,4^{\circ} \mathrm{C} \\
6 \mathrm{~mol}^{-1} \mathrm{I}^{-1} \mathrm{Gu} \mathrm{HCl}, \mathrm{pH} 7,4^{\circ} \mathrm{C}\end{array}$ \\
\hline$\kappa$ & $\begin{array}{r}9,5 \\
15,1 \\
31\end{array}$ & 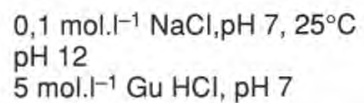 \\
\hline
\end{tabular}

(d'après Fox et Mulvihill, 1983) 


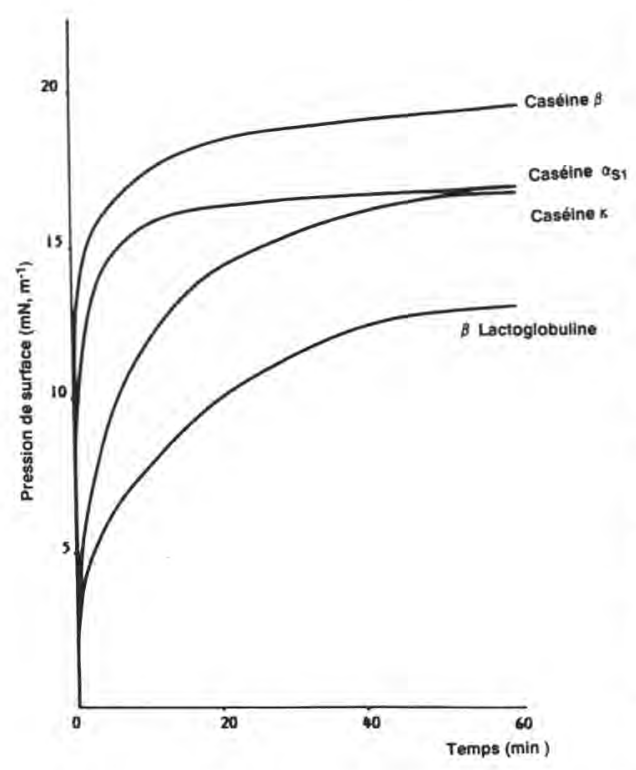

Fig 1. Cinétique d'augmentation de la pression de surface exercée par les caséines à l'interface eau/air à $\mathrm{pH} 7$ concentration protéique : $2.10^{-3}$ g..$^{-1}$.

Surface pressure versus time of casein solutions at $\mathrm{pH}$ 7. Protein concentration: $2.10^{-3} \mathrm{~g} \cdot \mathrm{t}^{-1}$.

vée, leur surface est très polaire ce qui, quel que soit le $\mathrm{pH}$, les rend très solubles (jusqu'à $300 \mathrm{~g} / \mathrm{l}$ pour la $\beta$-lactoglobuline). Comme la plupart des protéines globulaires, les protéines de lactosérum et plus particulièrement la $\beta$-lactoglobuline gélifient très facilement à la chaleur en raison d'une dénaturation (interactions hydrophobes, échange de ponts disulfures) et entraîne un changement de structure spatiale (Dumay, 1988); les gels, granuleux et opaques en milieu acide, élastiques et translucides en milieu neutre et alcalin, possèdent une excellente rétention d'eau, surtout en milieu neutre et alcalin. Les traitements thermiques sont à la base d'un grand nombre de procédés d'amélioration des propriétés fonctionnelles (Cheftel et Lorient, 1982). Leur structure très com- pacte, stabilisée par des ponts disulfure, les rend aptes à former des fims interfaciaux épais et rigides (surtout au pHi : 5,2 pour la $\beta$-lactoglobuline) même si leur aptitude à s'adsorber est plus faible que celle des caséines; il en résulte d'excellentes propriétés stabilisantes des mousses et émulsions à tous les $\mathrm{pH}$. Naturellement, la plupart des propriétés fonctionnelles des protéines globulaires dépendent de l'état plus ou moins dénaturé. Par traitement thermodénaturant, on peut ainsi accroître le pouvoir de rétention d'eau, ainsi que les propriétés tensioactives, à condition qu'on opère à des $\mathrm{pH}$ différents des $\mathrm{pHi}(5,2$ pour la $\beta$-lactoglobuline, 4,8 pour l' $\alpha$ lactalbumine). La $\beta$-lactoglobuline agit en général comme un meilleur agent tensioactif que l' $\alpha$-lactalbumine, surtout si elle est purifiée (Closs, 1990): ces résultats semblent contradictoires à ceux de de Wit et al (1988), mais il se pourrait qu'une dénaturation partielle des concentrés protéiques étudiés par ces auteurs suffise à accroître assez considérablement les propriétés tensioactives de l' $\alpha$-lactalbumine selon les observations de Closs mentionnées à la fin de cet article. La corrélation entre hydrophobicité de surface et propriétés de surface s'applique assez bien pour la $\beta$-lactoglobuline : meilleures propriétés moussantes en raison d'une forte hydrophobicité moyenne, propriétés émulsifiantes satisfaisantes à l'état dénaturé en raison d'une faible hydrophobicité de surface. Cependant, ces conclusions dépendent beaucoup des méthodes de mesure de I'hydrophobicité de surface (Shimizu et al, 1986).

\section{Relations entre flexibilité et structure spatiale}

La flexibilité des molécules est une propriété dynamique qui est étroitement liée à l'état d'hydratation et à la structure spa- 
tiale. On peut d'ailleurs assez bien suivre l'état d'hydratation d'un caséinate par l'augmentation par hydratation de la mobilité d'une chaîne latérale aminée (Blond et Le Meste, 1988) (fig 3). La mesure de la flexibilité des molécules peut être effectuée par de nombreuses méthodes physiques ou physico-chimiques : fluorescence, spectroscopie infrarouge, résonance magnétique nucléaire (RMN) et résonance paramagnétique électronique (RPE) (Kaivarainen, 1985). Pour cette dernière méthode, la mobilité des chaînes latérales se mesure grâce au marquage des chaînes par des radicaux nitroxydes doués de propriétés paramagnétiques. La flexibilité est exprimée par la fréquence de réorientation des résidus aminés de la protéine marquée qui dépend de 2 types de mouvements : les mouvements des groupes $\mathrm{N}-0$ et la flexibilité de la protéine elle-même.

Pour les caséines, Colas et al (1988) ont démontré que la mobilité des chaînes latérales de caséine restant en solution est maximale aux environs du $\mathrm{pHi}$ (fig 4). Dans un article plus récent, Le Meste et al (1990) montrent aussi que la mobilité des groupes marqués est plus importante pour les caséines $\alpha_{s 1}$ et $\beta$ que pour les caséines $\kappa$ et surtout très supérieure à celle des groupes marqués sur les protéines globulaires ( $\beta$-lactoglobuline et $\alpha$ lactalbumine). Closs (1990) montre, par ailleurs, que la mobilité de l' $\alpha$-lactalbumine est supérieure à celle de la $\beta$ lactoglobuline et que les effets sont les plus marqués à proximité des $\mathrm{pHi}$, en raison de la diminution des répulsions électrostatiques. La plus grande mobilité de l' $\alpha$ lactalbumine serait due principalement au positionnement des marqueurs nitroxydes sur des groupes aminés à proximité des extrémités $C$ et $N$ terminales très libres et flexibles, ce qui n'est pas le cas pour la $\beta$ lactoglobuline (groupes \& $\mathrm{NH}_{2}$ situés dans les zones très structurées).

Un déplissement de la $\beta$-lactoglobuline et de l' $\alpha$-lactalbumine par réduction et carboxyméthylation des ponts S-S accroît également la flexibilité des molécules, alors que la dénaturation thermique ne semble pas avoir d'effets significatifs sauf si les protéines précipitent, auquel cas la mobilité est fortement réduite. Ces observations sur la mobilité et la flexibilité peuvent être facilement reliées non seulement
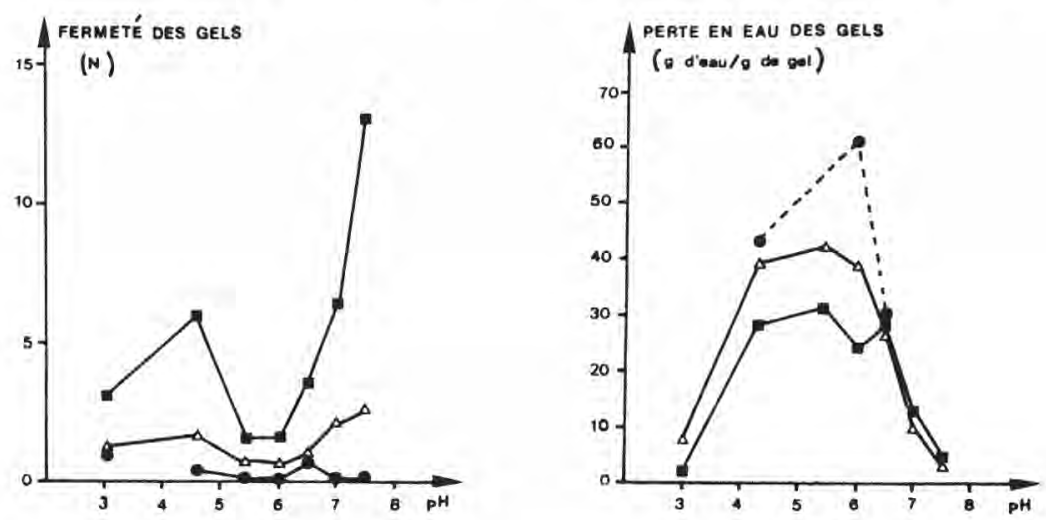

Fig 2. Évolution de la fermeté et de la perte en eau des gels de concentré protéique de lactosérum en fonction du $\mathrm{pH}$ et pour diverses teneurs en protéines (d'après Dumay, 1988).

- $7,6 \%$; $\Delta 9,4 \%$; $12 \%$. Influence of $\mathrm{pH}$ and protein concentration on firmness and loss of water of whey protein concentrate gels (Dumay, 1988). 


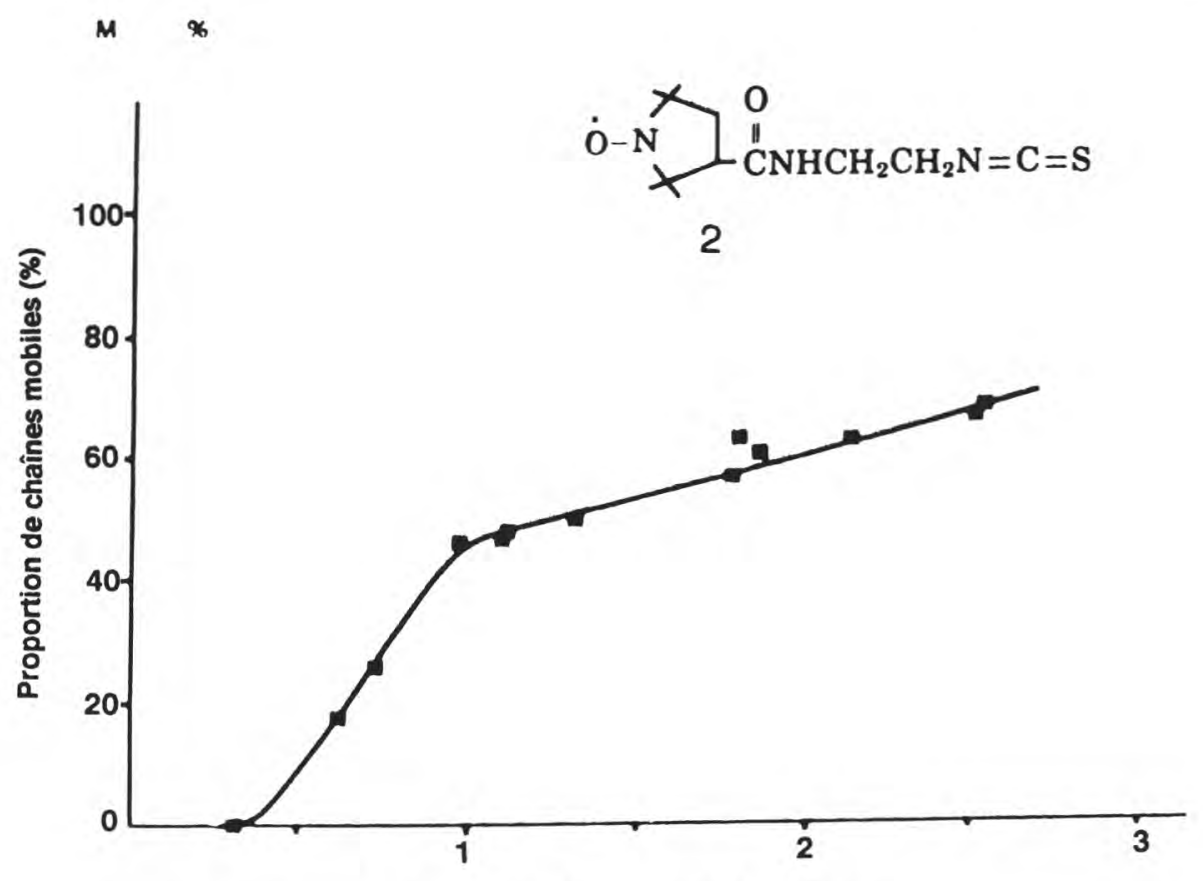

Teneur en eau $\mathrm{g} / \mathrm{g}$ de matière sèche

Fig 3. Processus de mobilisation des chaines $\xi$ aminées de la caséine marquées par des groupes nitroxydes. Mesures de la mobilité par RPE (d'après Blond et Le Meste, 1988).

Influence of the water content on the mobility of $\xi$ amino side chains of casein, labelled with nitroxide groups. Mobility measured by ESR (Blond and Le Meste, 1988).

à la structure plus ou moins déplissée des molécules, mais aussi aux comportements interfaciaux puisque les propriétés tensioactives sont les meilleures lorsque la mobilité est la plus élevée (protéines flexibles telles que les caséines ou les protéines globulaires déplissées, pHi, présence de sels, etc).

La mesure de flexibilité apprécie donc l'état dynamique de la protéine et son aptitude à interagir avec d'autres molécules de même nature ou de nature différente (eau, sels, glucides, lipides, tensioactifs).

Voluminosité et flexibilité peuvent être des indicateurs précieux de la potentialité fonctionnelle des protéines.

\section{COMPORTEMENT FONCTIONNEL DES PROTÉINES DU LAIT EN MÉLANGES}

\section{Interactions des protéines entre elles}

\section{Propriétés de surface des caséinates en mélange}

D'après la figure 6 , on constate qu'en général, les constituants purifiés sont souvent plus tensioactifs que le mélange (caséine entière) à partir duquel ils ont été isolés.

$\mathrm{Si}$ on constitue des mélanges en proportion variable des caséines $\alpha_{s 1}$, et $\beta$, les 


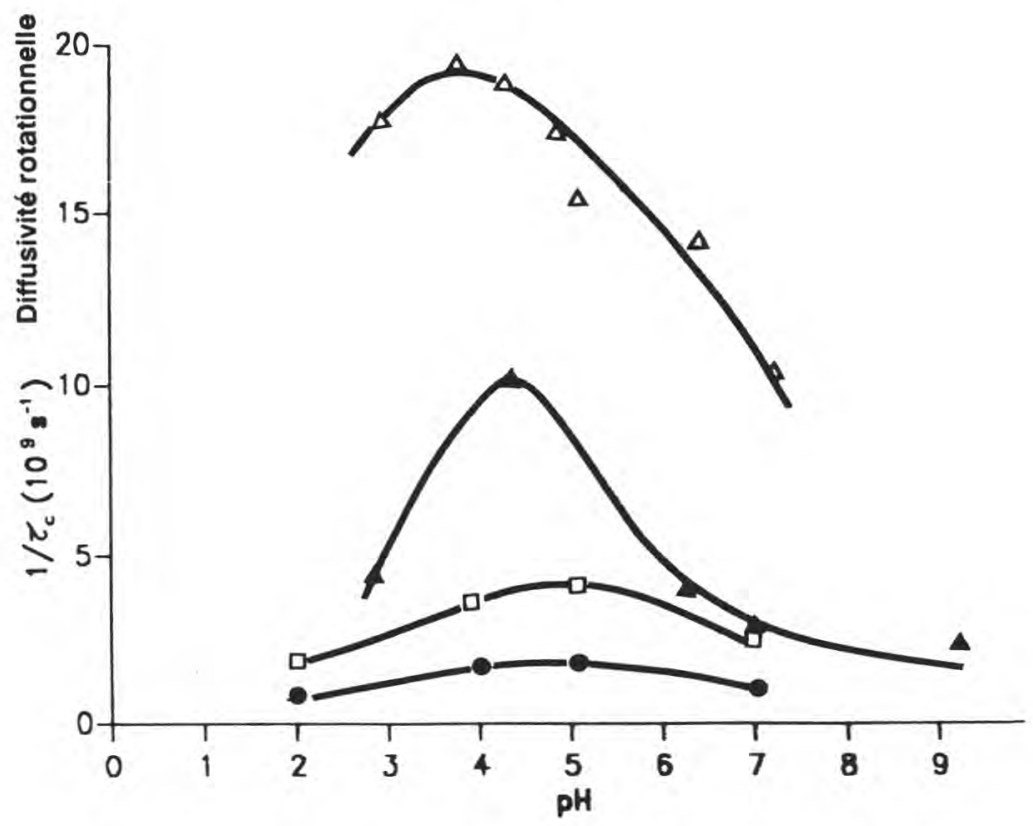

Fig 4. Influence du pH sur la diffusivité rotationnelle des protéines du lait (d'après Colas et al, 1988) $\Delta$ : caséinates $0,5 \mathrm{~g} . \mathrm{l}^{-1}$

$\Delta$ : caséinates $50 \mathrm{~g}^{. \mathrm{l}^{-1}}$;

ㄱ: $\alpha$ lactalbumine $25 \mathrm{~g} . \mathrm{I}^{-1}$;

- : $\beta$ lactoglobuline $25 \mathrm{~g} . \mathrm{l}^{-1}$.

Influence of $\mathrm{pH}$ on the rotational diffusibility of milk proteins.

propriétés émulsifiantes sont moins satisfaisantes qu'avec les constituants isolés, ceci étant plus marqué à $\mathrm{pH} 6$ qu'à $\mathrm{pH} 8$ (fig 7). On peut expliquer ce phénomène par le fait que dans ce cas les complexes en solution $\alpha_{s 1}-\beta$ sont plus stables que les complexes $\alpha_{s 1}-\alpha_{s 1}$ et $\beta$ - $\beta$ et qu'un nombre inférieur de monomères parvient à l'interface eau-huile pour abaisser la tension interfaciale (Cayot, 1989; Courthaudon, 1990). En ce qui concerne les propriétés moussantes, on observe un comportement inverse avec un effet de synergie (Cayot et al, 1990). Dickinson (1989) aborde la question plutôt sous un aspect cinétique; il constate en effet que, dans un mélange équimolaire, la caséine $\beta$ s'adsorbe en premier lieu, car sa diffusion est plus rapide, puis après équilibre reste prédomi- nante à l'interface (Brock et Enser, 1987; Dickinson et al, 1988). II observe aussi que la caséine $\beta$ injectée dans une solution de caséine $\alpha_{s 1}$ est capable de déplacer la caséine $\alpha_{\mathrm{s} 1}$ de l'interface d'émulsion (tétradécane/eau) mais que le comportement inverse est moins facile. Par contre, il ne semble pas y avoir de préférence pour l'interface eau/huile au cours de l'homogénéisation (Robson et Dalgleish, 1987). La caséine $\kappa$ semble jouer un rôle primordial Iorsqu'on l'ajoute aux solutions de caséine $\alpha_{s 1}$ ou $\beta$ puisque de récents travaux montrent que la caséine $\kappa$, beaucoup plus structurée, stabilise aussi bien les émulsions que les mousses de mélanges binaires. La caséine $\kappa$ jouerait de façon compétitive en dissociant les complexes $\alpha_{\mathrm{s} 1}-\beta$ et faciliterait ainsi la libération de mono- 

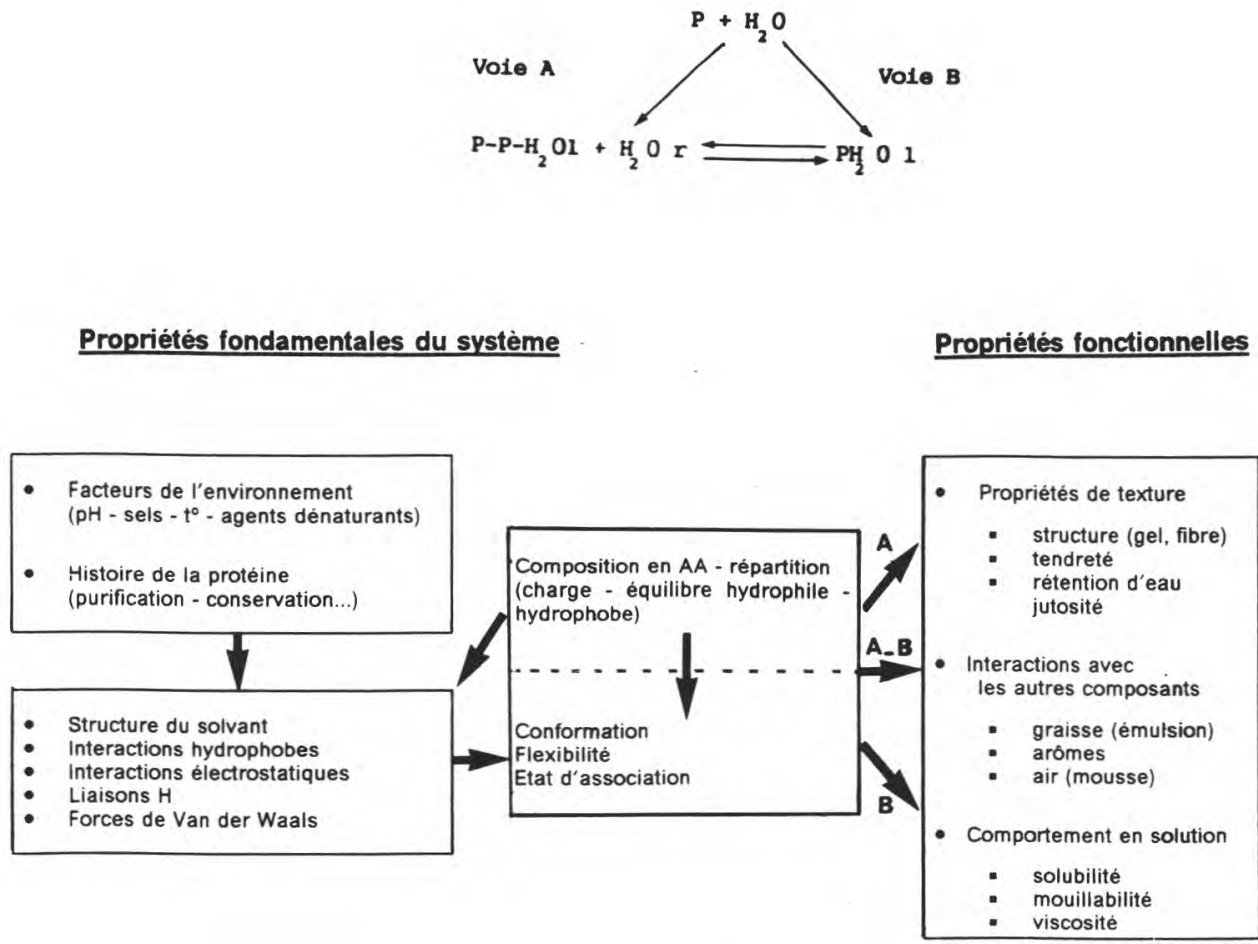

$P$ : protéine

P-P : interaction protéine-protéine

$\mathrm{p}-\mathrm{H}_{2} \mathrm{O} 1$ : interaction protéine- $\mathrm{H}_{2} \mathrm{O}$ "lièe

$\mathrm{H}_{2} \mathrm{O} \mathrm{r}: \mathrm{H}_{2} \mathrm{O}$ retenu dans la matrice protéique par des phénomènes capillaires

Voie A : interactions P-P favorisées

Voie B : interactions $\mathrm{P}-\mathrm{H}_{2} \mathrm{O}$ favorisées

Fig 5. Relations entre structure, propriétés physico-chimiques, dynamiques et fonctionnelles (d'après Blond et Le Meste, 1988).

Relationships between structure, physico-chemical, dynamic and functional properties (Blond and Le Meste, 1988).

mères de caséines $\alpha_{s 1}$ et $\beta$. Ces observations ne sont valables qu'à $\mathrm{pH}$ au moins égal à 6 , car à un $\mathrm{pH}$ proche de 4,5 c'est la solubilité plus ou moins grande de chaque constituant qui gouverne les propriétés moussantes (Closs et al, 1990).

\section{Propriétés de surface des protéines de lactosérum en mélange}

En général, l'activité émulsifiante et la capacité moussante des protéines purifiées sont supérieures à celles du lactosérum té- 


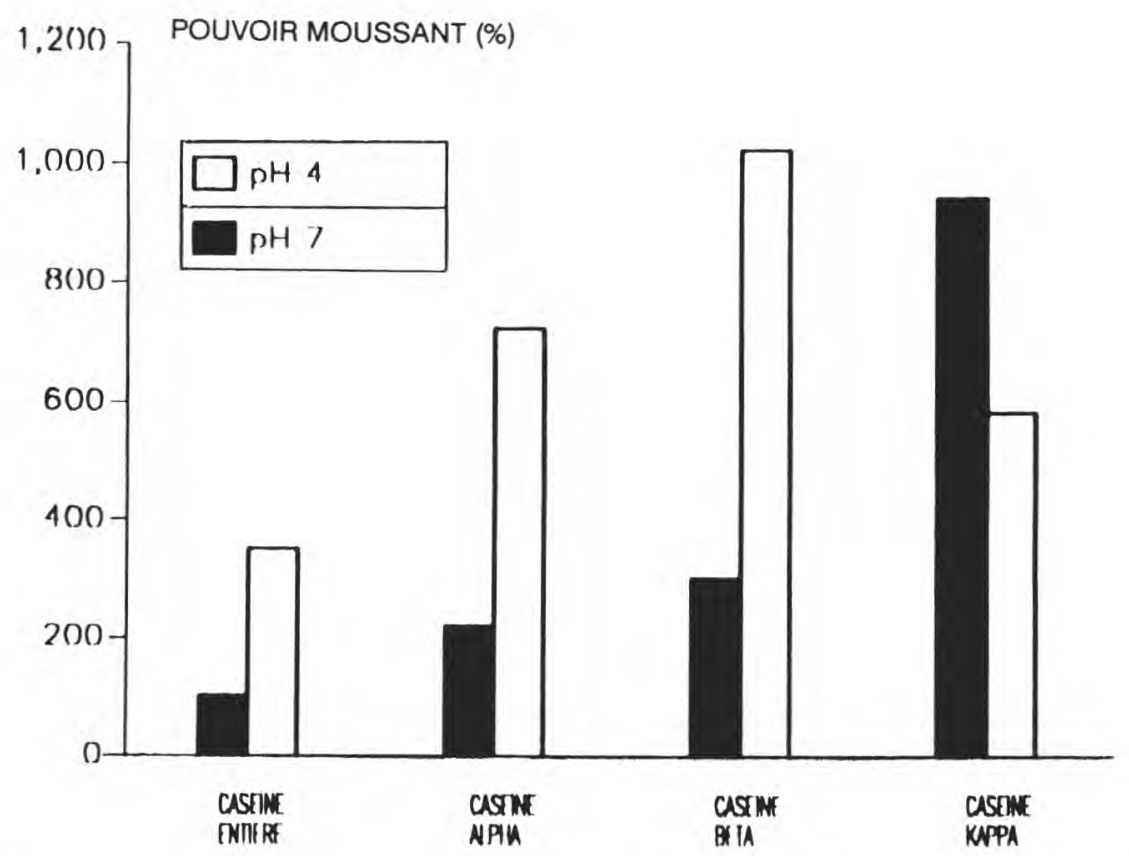

Fig 6. Capacité moussante de la caséine et des fractions en fonction du pH. Concentration protéique : $5 \mathrm{~g} . \mathrm{l}^{-1}$ (d'après Schmitt, 1990).

Foaming capacity of whole casein and casein components versus $\mathrm{pH}$. Protein concentration: $5 \mathrm{~g} . \mathrm{r}^{-1}$ (Schmitt, 1990).

moin, à la même concentration protéique (minimum au $\mathrm{pHi}$ pour l'activité émulsifiante, maximum au pHi pour la capacité moussante) (fig 8). II en est de même pour les stabilités émulsifiantes et moussantes (Closs, 1990) (figs 9 et 10). En mélange, on constate que la $\beta$-lactoglobuline est adsorbée majoritairement sur les globules gras, sauf à $\mathrm{pH}$ acide (tableau III d'après Leman et Kinsella, 1989), quels que soient les rapports de concentration des 2 protéines. Dickinson et al (1989a) observent également un comportement identique, mais il semble qu'après un long équilibre, les 2 protéines soient présentes à l'interface. Ces protéines forment des films interfaciaux élastiques et visqueux ( 1100 et
$350 \mathrm{mN} . \mathrm{s} . \mathrm{m}^{-1}$ pour la $\beta$-lactoglobuline et l' $\alpha$-lactalbumine respectivement) contre $100 \mathrm{mN} . \mathrm{s} . \mathrm{m}^{-1}$ pour la gélatine, $8 \mathrm{mN} . \mathrm{s} . \mathrm{m}^{-1}$ pour le caséinate et $0,5 \mathrm{mN} . \mathrm{s} . \mathrm{m}^{-1}$ pour la caséine $\beta$. Une viscosité aussi élevée freine les remaniements interfaciaux. En général, la viscosité de surface de mélange est toujours plus faible que la somme des viscosités des constituants (Dickinson, 1986) ce qui expliquerait nos observations sur les émulsions. On peut expliquer les médiocres propriétés tensioactives du lactosérum par cet effet mélange négatif et aussi par la présence de substances antisurfactantes (lipides, lipoprotéines, immunoglobulines). La clarification du lactosérum permet l'élimination de 


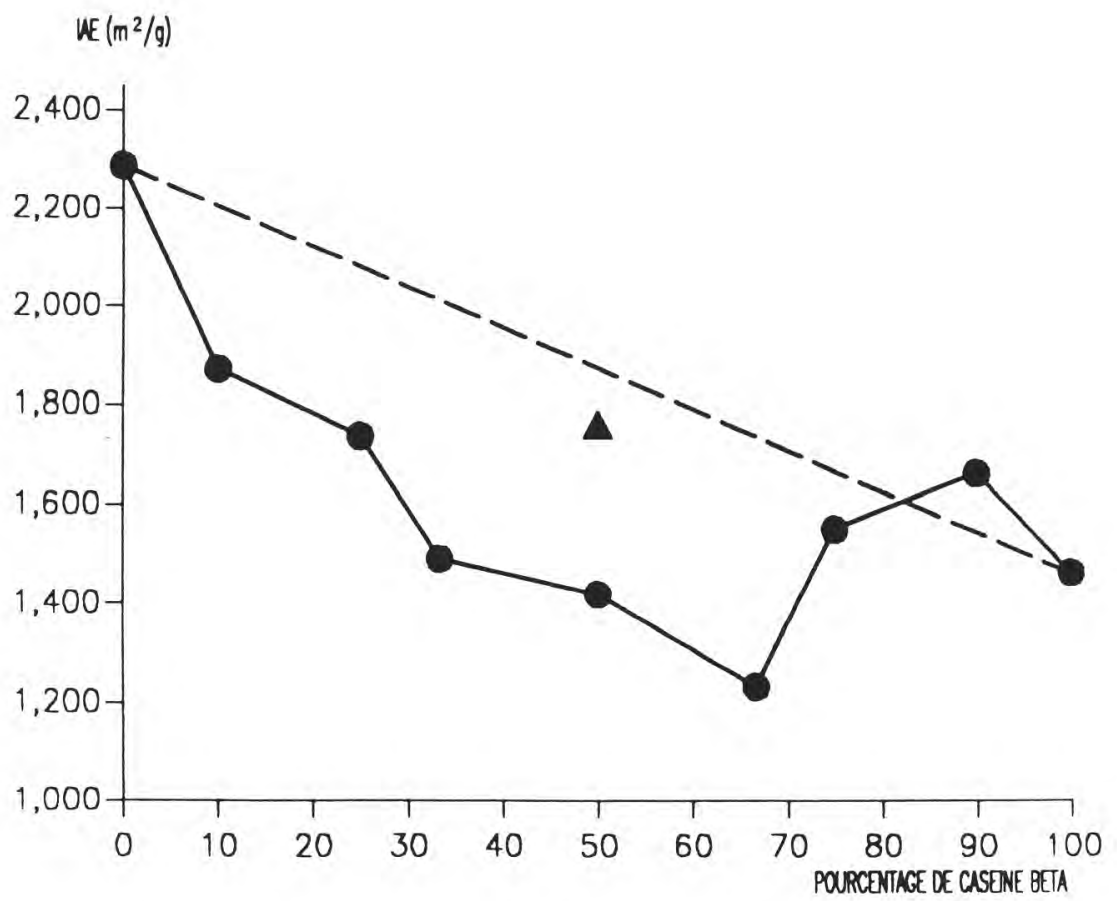

\section{COURBE OBSERVEE $\neq$ CASEINE TEMOIN + COURBE THEORIQUE}

Fig 7. Indice d'activité émulsifiante des mélanges de fractions caséiniques $(\mathrm{pH} 8$; fraction volumique de l'émulsion 0,25; concentration protéique $2,5 \mathrm{~g} . \mathrm{l}^{-1}$ (d'après Cayot, 1989).

Emulsifying activity index of mixtures of casein components $(\mathrm{pH} 8$; voluminal fraction of the emulsion, 0.25 ; protein concentration $2.5 \mathrm{~g} . \mathrm{t}^{-1}$ (Cayot, 1989).

ces substances et accroît considérablement les propriétés tensioactives; de même l'enrichissement en $\beta$-lactoglobuline de concentrés protéiques (procédé Sphérosil) explique les excellentes propriétés tensioactives de ceux-ci.

Les interactions observées sont souvent accrues par l'élévation de température surtout si celle-ci atteint les températures de dénaturation et provoque une gélification par échange de ponts disulfures; ces interactions ont été étudiées aussi bien sur des protéines pures isolées (Shimada et Cheftel, 1988; Paulsson et Dejmek, 1990; Relkin et Launay, 1990) sur des mélanges $\beta$ lactoglobuline / $\alpha$-lactalbumine bien caractérisés ou des concentrés de protéines de lactosérum (de Wit et Klarenbeck, 1984). Elles montrent qu'elles se font principalement par échange de ponts disulfures à 


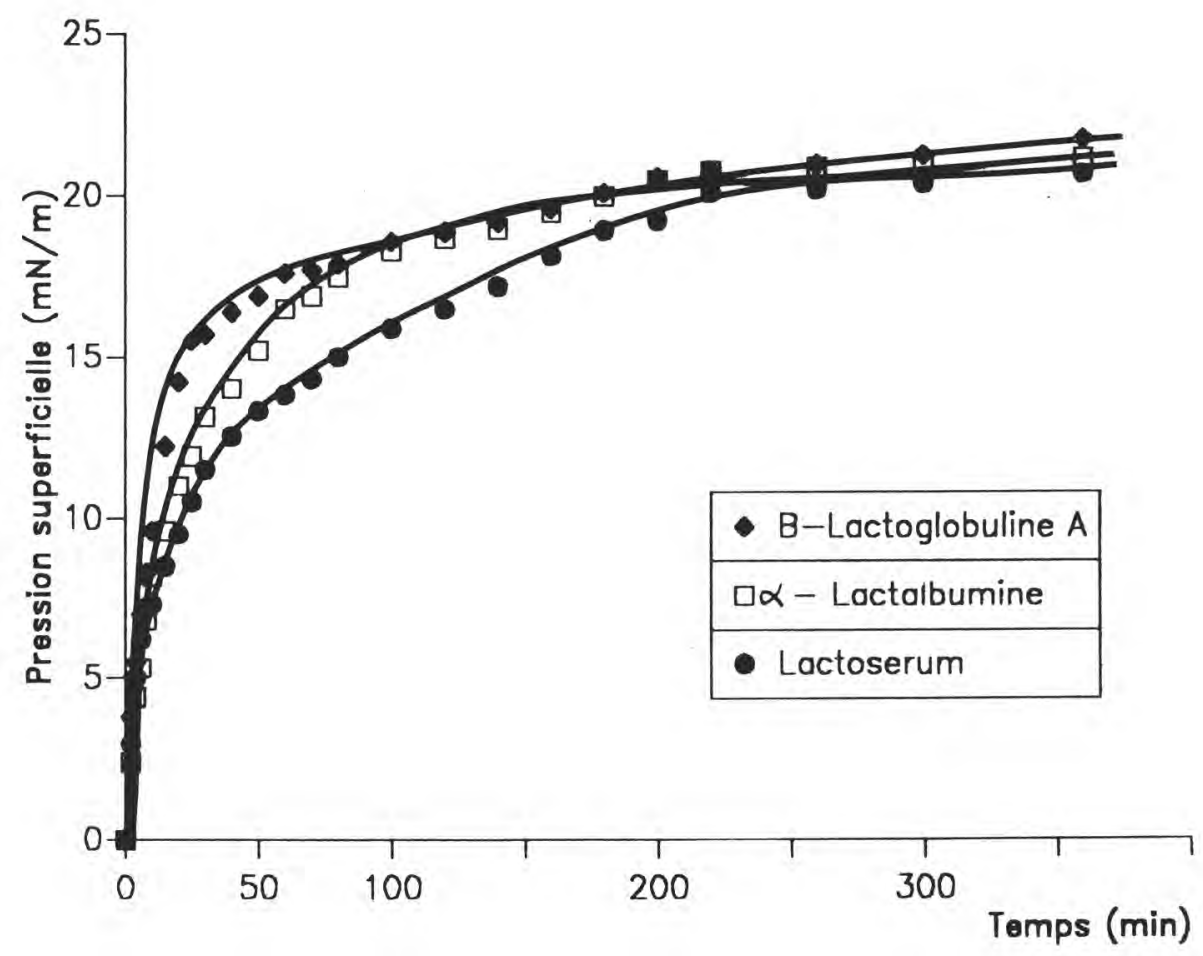

Fig 8. Pression superficielle du lactosérum et des protéines sériques à pH 4,8. Concentration protéique : $0,02 \mathrm{~g} . \mathrm{I}^{-1}$.

Surface pressure versus time of whey protein solutions at $\mathrm{pH} 4.8$. Protein concentration: $0.02 \mathrm{~g} . \mathrm{H}^{-1}$.

condition que la concentration soit au moins égale à $7-10 \%$ à un $\mathrm{pH}$ pas trop proche de 5,2.

\section{Interactions entre caséines et protéines du lactosérum}

Les suspensions de lait écrémé contenant $40-60 \%$ de matière sèche chauffées de 80 à $120^{\circ} \mathrm{C}$ peuvent former des gels dont la fermeté dépend de la température de chauffage (Kalab et Emmons, 1972); de même, le chauffage et l'acidification simultanés du lait écrémé non concentré provoquent la coprécipitation des caséines et des protéines du lactosérum. Malgré leur faible réactivité, les constituants caséiniques interagissent donc avec les protéines solubles. Bien que ne présentant pas de pic endothermique en analyse enthalpique différentielle, les caséines peuvent modifier les thermogrammes des protéines de lactosérum; l'addition à celles-ci de $5 \%$ de caséine $\alpha_{S}$ abaisse la température de dénaturation de $2-3{ }^{\circ} \mathrm{C}$ alors que la caséine $\beta$ n'a aucun effet. La caséine $\kappa$ n'affecte pas le comportement thermique de l' $\alpha$ lactalbumine, alors qu'elle abaisse la température de dénaturation de la $\beta$ lactoglobuline de $3{ }^{\circ} \mathrm{C}$ (Paulsson et Dejmek, 1990). Ce comportement est à appro- 


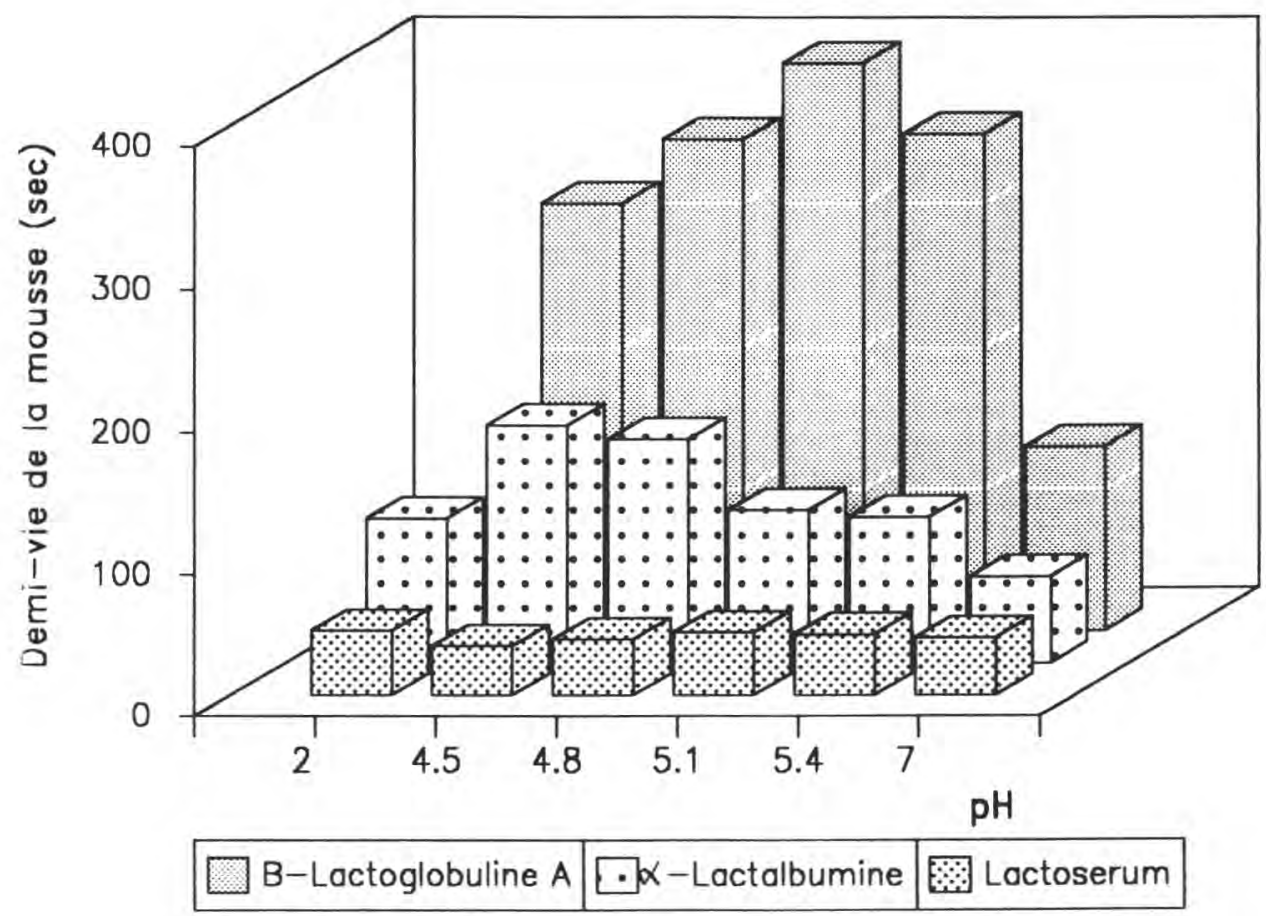

Fig 9. Stabilité de mousse des protéines de lactosérum en fonction du $\mathrm{pH}$. Concentration protéique 1 g..$^{-1}$.

Foaming stability of whey proteins versus $\mathrm{pH}$. Protein concentration: $1 \mathrm{~g} . \mathrm{H}^{-1}$.

cher de la formation du complexe $\beta$ lactoglobuline-caséine $\kappa$ (Haque et al, 1987), elle-même due à l'établissement d'un pont disulfure intermoléculaire (Jang et Swaisgood, 1990). D'autres auteurs constatent également que la surface de la micelle adsorbe la $\beta$-lactoglobuline et l' $\alpha$ lactalbumine au cours du chauffage; ces protéines se trouvent sous forme de filaments (en microscopie électronique) et limitent la dissociation de la micelle au cours de l'acidification lactique, d'où une incidence sur la texture d'un coagulum tel que le yaourt (Mottar et al, 1989). Par marquage des protéines du lactosérum au ${ }^{14} \mathrm{C}$, Noh et Richardson (1989) peuvent ainsi suivre l'incorporation successive de la $\beta$-lactoglobuline puis de l' $\alpha$-lactalbumine dans les micelles de caséine lors de traitements thermiques analogues à la pasteurisation, au préchauffage ou à la stérilisation UHT.

\section{Interactions entre les protéines du lait et les autres protéines : compétition aux interfaces}

Les caséines peuvent agir en compétition aux interfaces avec une protéine sans structure ordonnée comme la gélatine. Celle-ci est moins hydrophobe et plus poly- 


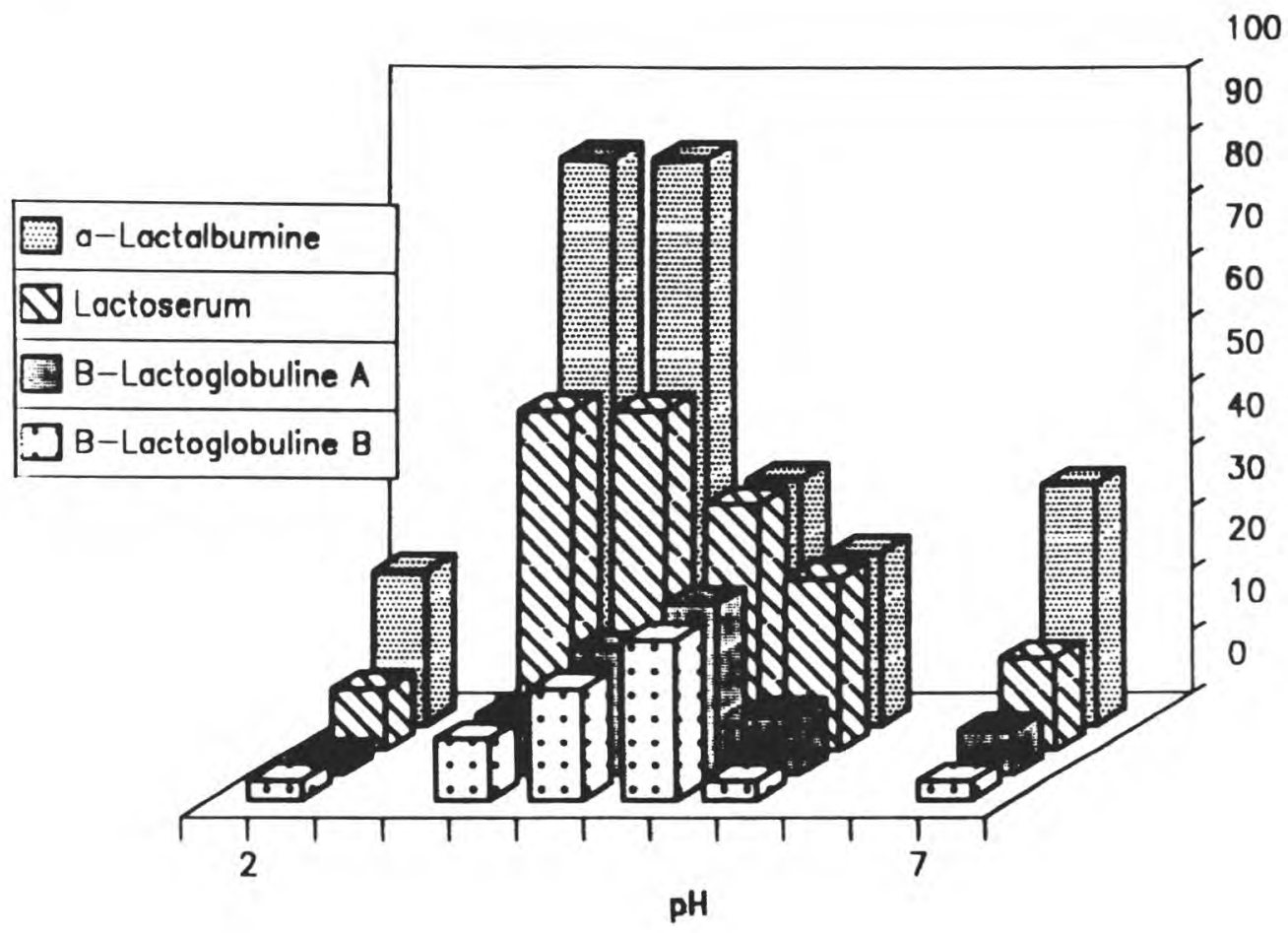

Fig 10. Influence du pH sur la coalescence des émulsions de protéines sériques. Concentration protéique $1 \mathrm{~g} . \mathrm{I}^{-1}$.

Influence of $\mathrm{pH}$ on the coalescence of whey protein emulsion. Protein concentration $1 \mathrm{~g} . \mathrm{t}^{-1}$.

Tableau III. Concentration relative (\%) des protéines de lactosérum dans la fraction protéique adsorbée sur la surface du globule gras d'émulsions à différents $\mathrm{pH}$.

Relative concentration of whey proteins in the protein fraction adsorbed on the fat globule surface of emulsions at various $\mathrm{pH}$ values.

\begin{tabular}{lrrrr}
\hline & \multicolumn{5}{c}{$p H$} \\
\cline { 2 - 5 } Protéines & 3 & 5 & 7 & \multirow{2}{*}{9} \\
& & & 46,1 & 61,6 \\
$\beta$-Lactoglobuline & 12,9 & 16,6 & 11,0 & 9,9 \\
$\alpha$-lactalbumine & 48,3 & 24,4 & 31,3 & 20,1 \\
Caséine + immunoglobulines & 34,1 & 40,0 & 2,7 & 1,0 \\
Sérumalbumine & 1,0 & 10,6 & 8,9 & 7,4 \\
Transferrine + lactoferrine & 3,7 & 8,4 & & \\
\hline
\end{tabular}

(d'après Leman et Kinsella, 1989) 


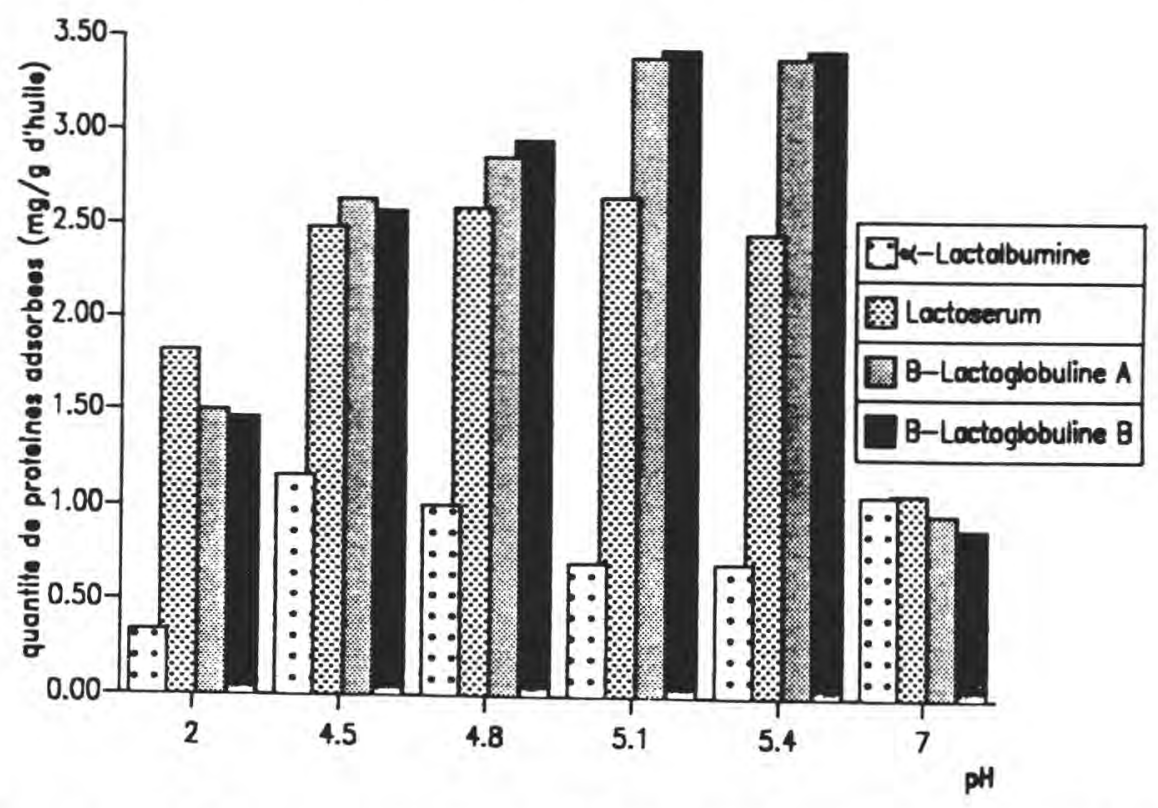

Fig 11. Quantité de protéines adsorbées dans la phase apolaire d'émulsions en fonction du pH. Concentration protéique $1 \mathrm{~g} . \mathrm{l}^{-1}$.

Influence of $\mathrm{pH}$ on the amount of adsorbed proteins during the apolar phase of the emulsions. Protein concentration: 1 g..$^{-1}$

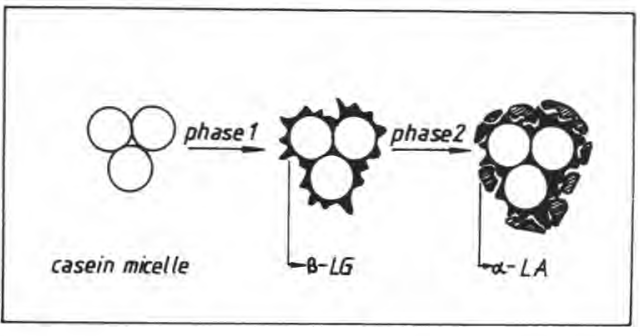

Fig 12. Modèle montrant les effets du chauffage sur la surface micellaire (d'après Mottar et al, 1989).

Scheme showing the effects of heat treatment on the micellar surface (Mottar et al, 1989).

dispersée que la caséine; de plus, elle peut gélifier en solution et au niveau des interfaces. Ces 2 protéines sont d'ailleurs associées dans des émulsions foisonnées comme les crèmes glacées. D'après Mussellwhite (1966) cité par Dickinson (1986), il existe une adsorption préférentielle de la caséine à la surface d'une solution contenant gélatine et caséine; la concentration superficielle en caséine est toutefois insuffisante pour saturer la surface et on pense que les 2 protéines coexistent dans une sorte de mosaïque interfaciale; on ne sait toutefois pas comment ces 2 sortes de molécules sont agencées.

Des études cinétiques sur des solutions montrent que la caséine peut déplacer graduellement la gélatine en totalité s'il y a suffisamment de caséine dans la solution.

La gélatine forme dans les émulsions huile-eau des films interfaciaux beaucoup plus visqueux que la caséine. Les 2 protéines jouent donc un rôle complémen- 
taire : tensioactivité pour la caséine, stabilisation du film interfacial pour la gélatine à condition que la caséine ne soit pas en concentration trop élevée $(\approx 25 \%)$.

Dans le cas de mélanges $\beta$ lactoglobuline-gélatine, on constate que la $\beta$-lactoglobuline est moins apte à freiner l'adsorption interfaciale de la gélatine que la caséine. Cependant, dans des émulsions à base de lait (crèmes glacées), les micelles de caséine peuvent participer à la réticulation du système gélifié comme le font les protéines du lactosérum après homogénéisation. Après lavage des globules gras, ce sont les protéines du lactosérum qui sont désorbées préférentiellement. Une dénaturation thermique peut retarder cette désorption. Dans les mélanges caséine + gélatine, les films interfaciaux formés sont moins visqueux que ce qu'on aurait pu attendre sur la base des viscosités de surface des composants purs.

II existe bien d'autres systèmes protéiques où l'addition de protéines laitières modifie le comportement rhéologique du milieu. Les systèmes œuf/lait, protéines de céréales/lait, protéines de soja/lait, bien que complexes, devraient susciter un intérêt de la part des physico-chimistes car une meilleure connaissance de la compatibilité de ces ingrédients au cours de la préparation des aliments s'avère nécessaire au moment de la formulation.

\section{Interactions des protéines du lait avec les polysaccharides}

II serait difficile de citer tous les travaux relatif́s à ce thème, puisque les polysaccharides gélifiants sont utilisés depuis plusieurs dizaines d'années pour stabiliser les protéines du lait contre la précipitation par les ions $\mathrm{Ca}^{2+}$. On peut faciliter la gélification des protéines dans les desserts laitiers, entremets et crèmes glacées. De même, il est bien connu qu'on peut précipi- ter une protéine par un polysaccharide chargé négativement (alginate, carraghénane, carboxyméthylcellulose, etc) dans le but de l'extraire sous forme d'isolat (Ledward, 1978; Cherry, 1982).

Les études les plus importantes portent sur les interactions entre caséines et le $\kappa$ carraghénane et l'aptitude de ce polysaccharide à stabiliser les caséines contre l'action des ions $\mathrm{Ca}^{2+}$ et à gélifier en leur présence si les conditions de concentrations sont remplies.

Initialement, il avait été établi que l'interaction entre la caséine $\kappa$ et le $\kappa$ carraghénane était de nature électrostatique car la caséine $\kappa$ possède une région très fortement chargée positivement capable d'interagir avec les groupes sulfate du $\kappa$-carraghénane. Des études plus récentes montrent que le $\kappa$-carraghénane est aussi capable de stabiliser vis-à-vis des ions $\mathrm{Ca}^{2+}$ toutes les protéines sensibles à ces ions, même à un $\mathrm{pH}$ proche $\mathrm{du} \mathrm{pHi}$ : caséines $\alpha_{\mathrm{s} 1}$ et $\beta$, paracaséine, protéines de soja, d'arachide et de coton.

D'autres travaux visent à étudier les interactions avec des polysaccharides épaississants tels que les gommes (caroube ou guar, xanthane) et peut être avec un nouveau gélifiant possédant des charges positives aminées, le chitosane.

\section{Interactions entre protéines et surfactants}

En plus des macromolécules amphipolaires telles que les protéines, des petites molécules surfactantes peuvent s'adsorber aux interfaces eau/huile. La façon dont ces 2 types de molécules se répartissent entre l'interface et les 2 phases détermine la formation, la stabilité et la texture des émulsions alimentaires (sauces pour salades, crèmes glacées, etc); ces molécules entrent en compétition pour occuper des 
sites à l'interface et abaisser la tension interfaciale.

La présence de surfactants de faible masse moléculaire peut intervenir sur la formation et la stabilisation d'émulsions et mousses alimentaires de différentes manières selon Dickinson et al (1990) :

- la présence de surfactants provoque, au cours de l'homogénéisation, une diminution de la taille des gouttelettes d'huile en raison d'un abaissement plus important de la tension interfaciale;

- les surfactants déplacent de l'interface les protéines impliquées dans la floculation, accroissent la dispersion des gouttelettes et diminuent la viscosité de l'émulsion;

- les surfactants peuvent interagir avec les protéines adsorbées en formant un film épais et résistant;

- la stabilisation de l'émulsion peut être aussi assurée par la présence de cristaux liquides aux interfaces eau-huile ou eauair.

Les émulsions sont déstabilisées par l'accroissement du regroupement des globules par rupture partielle des couches protéiques interfaciales durant le battage ou le foisonnement.

Les surfactants interagissant avec les protéines sont classés en 3 catégories :

- les surfactants anioniques sont surtout représentés par des acides organiques à longue chaîne hydrocarbonée. Parmi eux, le sodium dodécyle sulfate (SDS) est largement utilisé pour solubiliser des macromolécules hydrophobes dans l'eau. La fixation du SDS sur les protéines par interaction hydrophobe a été exploitée pour la mesure de l'hydrophobicité de surface (Kato et al, 1984) des protéines; en effet, à faible concentration de surfactant, le taux de fixation est proportionnel à l'hydrophobicité de surface. Dans le cas de la caséine, il décroît lorsque le $\mathrm{pH}$ s'élève en raison de l'accroissement des répulsions électrostatiques entre protéine et SDS;

- les surfactants cationiques sont moins bien connus. En général leur fixation en fonction du $\mathrm{pH}$ et de la force ionique correspond à un comportement purement électrostatique seulement à faible concentration en surfactant;

- les surfactants non ioniques peuvent être utilisés pour extraire des protéines membranaires sans modification de la conformation native; leur interaction est très efficace avec les protéines lipophiles: les mono- et diglycérides sont représentés dans cette catégorie.

En général, à concentration massique égale, des petites molécules amphipolaires sont plus tensioactives que les protéines; en effet, elles déplacent les protéines de la surface des gouttelettes d'émulsions au-delà d'une concentration critique. On peut suivre ce déplacement en enregistrant la tension interfaciale en fonction du logarithme de la concentration en surfactant. Sur la figure 13 , on constate qu'un accroissement de la concentration en surfactant (ici, l'octaoxyéthylène dodécyléther) dans l'eau abaisse la tension interfaciale jusqu'à une valeur seuil minimale. En présence de caséinate à faible concentration, la tension interfaciale initiale est plus faible, mais elle évolue de la même façon en atteignant la même valeur seuil pour la même concentration, ce qui veut dire que toute l'interface est saturée par le surfactant.

II est difficile de prédire les différences de comportement des surfactants; en effet, Dickinson et al (1989b) constatent que dans des émulsions laitières contenant de l'alcool, le taux de déplacement du caséjnate adsorbé à la surface d'une gouttelette d'huile est similaire pour les 2 types de surfactants étudiés : monostéarate de glycérol (non ionique liposoluble) et stéaroyle lactylate de sodium (anionique et soluble dans 


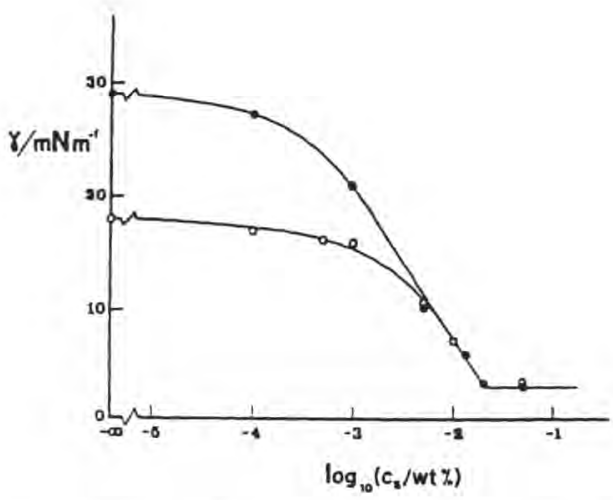

Fig 13. Tension interfaciale d'une solution de caséinate et d'un surfactant (octaoxyéthylène éther) à l'interface eau - $\mathrm{n}$ tétradécane (tampon $20 \mathrm{mmol} / \mathrm{l}$ imidazole $\mathrm{pH} 7,25^{\circ} \mathrm{C}$ ) en fonction du logarithme de la concentration du surfactant (d'après Woskett, 1989).

- : surfactant seul $\quad 0: 0,1 \%$ de protéine. Influence of the surfactant concentration on the interfacial behavior of the casein ( $P 20 \mathrm{mmol}^{\mathrm{t}^{-1}}$ imidazole buffer, $\mathrm{pH} 7,25^{\circ} \mathrm{C}$ ) (Woskett, 1989).
-: Surfactant alone;
0 : with $0.1 \%$ protein.

l'eau). Même à forte concentration en surfactant $(2 \%)$ le déplacement n'est pas complet. Laliberté et al (1988) avaient également observé que le monostéarate de glycérol ne peut déplacer totalement d'une interface eau-air la couche de caséinate; il semble que le caséinate et le monoglycéride forment un complexe stable en surface.

\section{Rôle des microstructures dans les interactions aux interfaces: exemple des mousses de lait et des crèmes fouettées (crèmes glacées) (Anderson et Brooker, 1988)}

\section{Mousses de lait écrémé}

Ce sont des structures complexes contenant des protéines du lait et dont la forma- tion et la stabilité sont influencées par la température, la teneur en lipides et la présence de surfactants lipidiques comme les monoglycérides et les phospholipides. Des observations par microscopie électronique montrent que les lamelles de bulles d'air formées dans le lait sont composées d'une couche interfaciale de $5 \mathrm{~nm}$ d'épaisseur à laquelle sont fixées des micelles de caséine (fig 14.1). Au cours du temps, la surface des bulles diminue en raison de la coalescence; cette évolution serait associée à l'accroissement des concentrations interfaciales des constituants ou à la désorption de ceux-ci à l'interface; de plus, on observe des plissures en surface des bulles, ce qui perturbe les liaisons entre les bulles.

Les micelles ne représentent qu'une partie de l'interface air-sérum; la $\beta$ lactoglobuline, l' $\alpha$-lactalbumine et la caséine $\beta$ y sont préférentiellement adsorbées; la caséine $\beta$ serait adsorbée d'abord surtout si, à basse température, elle peut être déplacée de la micelle; les 2 autres protéines se fixeraient alors en formant des films mixtes.

Pour expliquer la façon dont les micelles s'adsorbent, on peut considérer que la $\beta$-lactoglobuline adsorbée est en partie dénaturée et démasque des groupes thiols libres; ceux-ci réagiraient ensuite avec les groupes thiols de la caséine $\kappa$ située à la périphérie de la micelle; d'autres types d'interactions pourraient être impliqués (hydrophobe ou électrostatique). La présence de micelles ne serait pas un facteur de stabilité des mousses laitières puisque celles-ci se déstabilisent $3-4$ fois plus vite que les mousses de sérum. Les lipides du lait réduisent le foisonnement à cause de l'adsorption à l'interface eau-sérum de molécules tensioactives et de globules gras entiers. De plus les produits de lipolyse sont des agents anti-mousse; les mono- et diglycérides sont surtout responsables de 


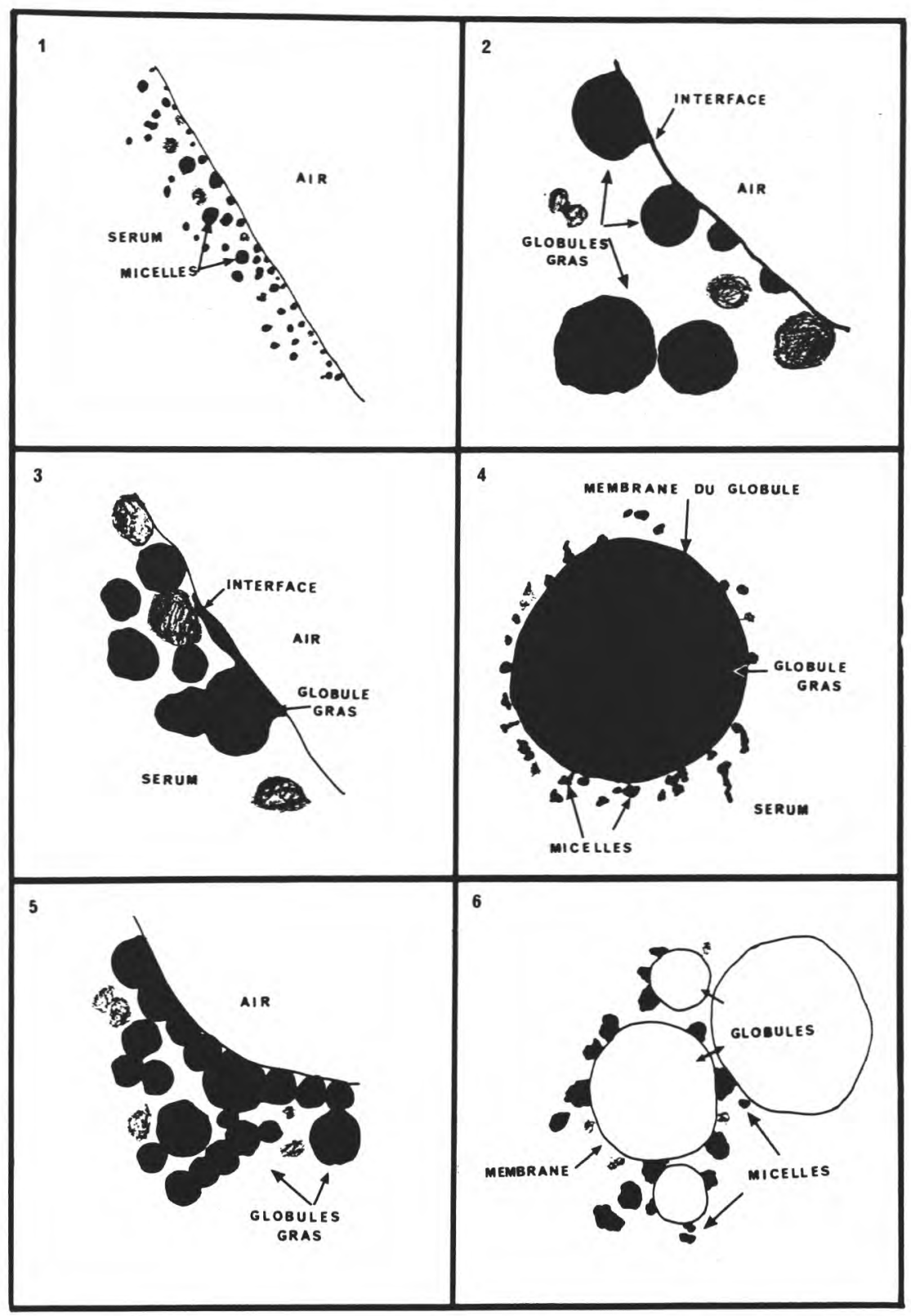

Fig 14. Schémas représentant les interfaces eau/air et eau/huile dans les laits et crèmes; 1 : interface air-eau dans le lait écrémé; 2 : interface air-eau dans le lait non écrémé; 3 et 5 : interface air-eau dans le lait non écrémé montrant l'étalement des globules gras et les lipides liquides; 4 et 6 : interfaces eau-globules gras montrant la fixation des micelles de caséines (d'après Anderson et Brooker, 1988). Schemes showing water/air and water/oil interfaces in milks and creams. 1: Air/water interfaces in skimmed milk. 2: Air/water interface in whole milk. 3 and $5:$ Air/water interface in whole milk showing the spreading of fat globules and liquid fat. 4 and 6 : Water fat globule interface showing the adsorption of the casein micelles (Anderson and Booker, 1988). 
cet effet. Les grandes variations dans le taux de foisonnement des échantillons de lait écrémé ne peuvent être dues ni au taux résiduel (très faible) de matière grasse, ni aux variations saisonnières de la composition du lait, bien que les teneurs en phospholipides soient assez fluctuantes. On considère plutôt que des chocs à basse température déstabilisent la micelle avec libération de caséine $\beta$; l'addition de celle-ci à du lactosérum provoque d'excellentes propriétés moussantes, surtout si on élimine préalablement le calcium par dialyse (tableau IV).

\section{Structure de la crème fouettée}

La crème fouettée peut être considérée comme une mousse de lait contenant des globules gras. L'étape initiale du fouettage implique une adsorption d'un nombre réduit de globules gras à la surface des bulles d'air (fig 14.2). Si des cristaux de lipides sont présents à l'interface huile-eau, une adsorption irréversible se produit dès qu'un cristal entre en contact avec l'interface air-eau. L'adsorption des globules provoque une perte partielle de la membrane de globules gras et une partie des lipides entre directement en contact avec l'air et fait saillie dans la bulle (fig 14.3,
14.5). La membrane au contraire reste en place du côté aqueux et forme une structure continue avec les protéines de l'interface air-sérum. Les stades suivants impliquent un accroissement progressif du taux d'agglomération des globules gras et du nombre de globules adsorbés, ainsi que des modifications dans le nombre et la taille des bulles. L'adsorption des globules est suivie par un étalement des lipides à l'interface et si les taux de liquide sont suffisants, les bulles s'effondrent en atteignant la surface de la crème; les globules sont libérés puis s'agglomèrent en raison de l'absence partielle de membrane.

Durant le fouettage, les micelles de caséine peuvent être associées à la surface des globules surtout dans le lait à basse température mais celà dépend beaucoup de la façon dont la membrane du globule est modifiée (fig 14.4). En fin de fouettage, la périphérie de chaque bulle est composée de globules gras partiellement agglomérés mais il reste un taux variable de l'interface d'origine air-sérum.

La stabilité de ces structures est souvent dépendante de la teneur en lipides, de la façon dont l'homogénéisation a été menée et aussi de la présence éventuelle d'agents émulsifiants ou de gélifiants (hydrocolloïdes, amidons modifiés) destinés à

Tableau IV. Influence de la caséine sur les propriétés moussantes du lactosérum. Influence of casein on whey foaming properties.

\begin{tabular}{ccccc}
\hline $\begin{array}{c}\text { Concentration } \\
\text { en caséine } \beta\end{array}$ & $\begin{array}{c}\text { Foisonnement } \\
\left(\mathrm{cm}^{3} \cdot \mathrm{ml}^{-1}\right)\end{array}$ & \multicolumn{2}{c}{$\begin{array}{c}\text { Stabilité } \\
\left(\mathrm{cm} \cdot \mathrm{h}^{-1}\right)\end{array}$} \\
$\left(m g \cdot \mathrm{r}^{-1}\right)$ & $N D$ & $D$ & $N D$ & $D$ \\
\hline 0 & 3,5 & 3,4 & 86 & 37 \\
1 & 3,3 & 3,5 & 35 & 6 \\
2 & 3,1 & 3,3 & 32 & 7 \\
\hline
\end{tabular}

d'après Anderson et Brooker (1988); ND : non dialysé; D : dialysé; ND; non dialysed; D: dialysed 
accroître la viscosité et la résistance mécanique de la phase aqueuse.

\section{Facteurs intervenant sur les propriétés des crèmes fouettées :}

- la teneur en protéine requise pour couvrir la surface des bulles d'air est faible; seulement $4 \%$ des protéines totales de la crème sont utilisées. L'élimination des protéines réduit le temps de fouettage et la fermeté; au contraire, lorsque les crèmes sont préparées à partir de lait concentré, le foisonnement est diminué alors que la fermeté est accrue;

- la teneur en lipides joue un grand rôle sur les propriétés rhéologiques. Lorsque la teneur en lipides passe de 25 à $45 \%$, la crème devient plus ferme, foisonne plus rapidement, le volume maximal étant atteint pour un taux de 30\%. La composition lipidique et le point de fusion qui en résulte sont également des facteurs importants;

- l'état de l'interface huile-eau peut varier considérablement : au moment du fouettage, si les globules gras sont déjà agrégés, la crème est ferme, les mousses formées sont fermes, peu foisonnées et le temps de fouettage est raccourci;

- la composition de l'interface influence grandement les propriétés foisonnantes; on sait, en effet, que les crèmes non homogénéisées donnent des mousses de meilleure qualité que les crèmes homogénéisées. En effet, l'homogénéisation rompt les membranes naturelles de globules gras et accroît la surface de l'interface eau-huile de 5-6 fois, la nouvelle interface étant constituée de protéines plasmatiques adsorbées et de caséine. Dans les crèmes homogénéisées, les micelles de caséine forment des ponts entre globules gras adjacents (fig 14.6). La stabilité de ces crèmes est surtout gouvernée par la qualité de l'émulsion; aussi des émulsifiants tels que monoglycérides, phospholipides peu- vent être utilisés. Ceux-ci forment une interface en s'adsorbant plus rapidement que les micelles; ces dernières n'occupent que la place laissée libre ou s'associent aux émulsifiants pour former une interface multiconstituants.

\section{Cas particulier des crèmes glacées}

Ce sont des mousses renfermant $50 \%$ d'air, $6-12 \%$ de lipides homogénéisés et $7,5-11,5 \%$ de lait écrémé. Le mécanisme de formation ressemble à celui des crèmes fouettées. La surface des bulles d'air est recouverte d'une fine couche d'huile provenant de la destructuration des globules gras. Initialement, les protéines sont adsorbées à l'interface air-eau, mais une seconde adsorption et une coalescence des globules gras se produiraient ensuite. Les émulsifiants pourraient même accélérer ce processus (Goff et Jordan, 1989; Goff et al, 1989).

\section{MODIFICATIONS DES PROPRIÉTÉS FONCTIONNELLES ET PROCÉDÉS D'AMÉLIORATION}

Les propriétés fonctionnelles dépendent de la structure des molécules présentes et, par conséquent, de tous les facteurs qui modifient:

- la composition de l'ingrédient considéré en protéines et autres substances de nature non protéique (sels, glucides);

- la structure des protéines (structure primaire et tridimensionnelle) et leur taille (hydrolyse ou polymérisation).

Les tableaux $V$ et VI classent les procédés d'amélioration selon les effets produits sur la structure et les propriétés fonctionnelles; ils reprennent les éléments principaux d'une précédente revue (Cheftel et Lorient, 1982) en y ajoutant de nouveaux 
procédés de fractionnement et de texturation.

\section{Amélioration par modification de la composition des ingrédients protéiques (tableau V)}

En général, l'élimination des substances minérales et de nombreuses substances dialysables (électro-dialyse, filtration sur gel) améliore sensiblement la plupart des propriétés fonctionnelles. Cependant, les plus grands progrès ont été réalisés sur l'ultrafiltration couplée à la diafiltration; ce procédé qui a surtout été utilisé pour la concentration, élimine une partie des sels et du lactose des matières premières laitières et peut être associé aux traitements thermiques comme pré ou post-traitement.

Parmi les plus récentes améliorations de la technique, on peut citer son utilisation comme procédé d'extraction de la caséine $\beta$ à partir de lait écrémé (Maubois et Léonil, 1989); ces auteurs mettent en jeu la dissociation partielle à basse température de la micelle de caséine et la "fuite" de la caséine $\beta$ ainsi que les caractéristiques d'état de surface et de perméabilité de nouvelles membranes minérales. On peut ainsi obtenir des concentrés enrichis en caséine $\beta$ et possédant de meilleures propriétés tensioactives.

Les progrès récents portent aussi sur l'utilisation des échangeurs d'ions pour enrichir ou purifier les constituants du lactosérum et des caséinates. Le procédé Sphérosil qui utilise un échangeur d'anions permet d'obtenir à l'échelle industrielle de la $\beta$-lactoglobuline très enrichie (85-95\%). Ces concentrés sont d'excellents gélifiants à une concentration protéique supérieure à $5 \%$, à $\mathrm{pH}$ neutre et une température de 70-85 ${ }^{\circ} \mathrm{C}$ (Shimada et Cheftel, 1988); ces gels fermes et élastiques présentent une bonne capacité de rétention d'eau. $\mathrm{Au} \mathrm{pHi}$ $(5-5,2)$, les réactions d'agrégation conduisent à un coagulum granuleux comme on peut l'obtenir aussi à un $\mathrm{pH}>5,5$ en présence d'ion $\mathrm{Ca}^{2+}$ et $\mathrm{Mg}^{2+}$ (Varunsatian et al, 1983). Sous forme partiellement dénaturée à $\mathrm{pH}$ neutre, ces concentrés sont aussi d'excellents agents foisonnants et émulsifiants. D'autres supports chromatographiques ayant une bonne résistance mécanique (Q Sepharose Fast Flow, DEAE Sephacel, etc) sont très facilement utilisables par des installations en "batch" (Lorient et Linden, 1990). Cette technique, qui est beaucoup moins coûteuse qu'une installation chromatographique et permet de traiter de grosses quantités de protéines, pourrait sans doute être transposée à l'échelle industrielle pour la purification des caséines en milieu urée concentrée.

\section{Amélioration par modification de la structure}

\section{Traitements thermiques}

Leurs effets dépendent beaucoup de la sévérité du traitement et des conditions de milieu $(\mathrm{pH}$, présence de sels en particulier d'ions divalents tels que $\mathrm{Ca}^{2+}$ ), ce qui pourrait expliquer la disparité et parfois les contradictions apparentes des résultats de la littérature.

Nous avons tenté de mieux comprendre l'effet dénaturant des traitements en fonction du $\mathrm{pH}$ sur les propriétés émulsifiantes et moussantes de la $\beta$-lactoglobuline et de l' $\alpha$-lactalbumine purifiées (95\%) (figs 15 et 16). Dans ces conditions, on constate par électrophorèse SDS-PAGE, qu'en milieu acide uniquement à partir de $90{ }^{\circ} \mathrm{C}-30$ min, des petits peptides apparaissent comme l'avait déjà observé lung (1988). Par électrophorèse en milieu non dissociant, on observe qu'à $70^{\circ} \mathrm{C}$, il y a une mo- 
Tableau V. Influence des traitements de fractionnement sur les propriétés fonctionnelles.

Influence of processing on the functional properties.

\begin{tabular}{|c|c|c|c|c|c|c|c|c|c|c|c|}
\hline \multirow[t]{2}{*}{ Traitement } & \multirow{2}{*}{$\begin{array}{l}\text { Produit } \\
\text { traité }\end{array}$} & \multirow[b]{2}{*}{ Rendement } & \multicolumn{3}{|c|}{ Composition moyenne } & \multirow[b]{2}{*}{$\mathrm{Li}(\%)$} & \multicolumn{5}{|c|}{ Propriétés fonctionnelles * } \\
\hline & & & $P(\%)$ & La (\%) & Mi (\%) & & $s$ & $H$ & G & $C E$ & $C M$ \\
\hline \multicolumn{12}{|c|}{ Modification de la composition } \\
\hline Électrodialyse & Lactosérum & & 35 & $40-60$ & 2 & 2,5 & 90 & & + & + & +1000 \\
\hline Filtration sur gel & Lactosérum & & $50-80$ & $8-25$ & 3-14 & $\varepsilon$ & $80-95$ & $0,5-1,8$ & + & +420 & +750 \\
\hline $\begin{array}{l}\text { Ultrafiltration } \\
\text { (+ diafiltration) }\end{array}$ & Lactosérum & $>90$ & $30-70$ & $15-55$ & $0,4-6$ & $\varepsilon$ & 90 & 0,5 & + & +400 & +900 \\
\hline $\begin{array}{l}\text { Ultrafiltration à } \\
\text { basse température }\end{array}$ & Lait écrémé & & & & & & & & & & \\
\hline Rétentat & & & 85 & & $5-15$ & $\varepsilon$ & 95 & + & + & & \\
\hline $\begin{array}{l}\text { Perméat } \\
\text { (caséine } \beta \text { ) }\end{array}$ & & & 95 & 0 & $\varepsilon$ & 0 & 98 & & & + & + \\
\hline \multicolumn{12}{|c|}{ Fractionnement par échange d'ions } \\
\hline $\begin{array}{l}\text { Procédé Vistec } \\
\text { (CM cellulose) }\end{array}$ & Lactosérum & & 95 & $\varepsilon$ & 3 & 0,5 & 98 & & + & & + \\
\hline $\begin{array}{l}\text { Procédé Sphérosil } \\
\text { (échange d'anions) } \\
\text { Q Sépharose }\end{array}$ & Lactosérum & $>90$ & $84-90$ & 0,5 & 3 & $<0,5$ & 98 & + & + & + & + \\
\hline Fast flow & $\begin{array}{l}\text { Lactosérum } \\
\beta \lg \end{array}$ & $>90$ & 95 & 0 & $\varepsilon$ & $\varepsilon$ & 98 & & + & & + \\
\hline Fast flow & $\begin{array}{l}\text { caséinates } \\
\text { caséine } \beta\end{array}$ & $>80$ & 95 & & & & 98 & & & + & + \\
\hline
\end{tabular}

* Solubilité (\%); H = Hydratation $\mathrm{ml} / \mathrm{g} ; \mathrm{G}=$ Gélification; $\mathrm{CE}=$ Capacité émulsifiante (ml huile/g); CM : capacité moussante (\%).

* Solubility (\%); $H$ = hydration $(\mathrm{ml} / \mathrm{g}) ; G=$ gellification; $C E=$ emulsifying capacity ( $\mathrm{ml}$ oil/g); $C M=$ foaming capacity (\%). 
Tableau VI. Influence des traitements thermiques sur les propriétés fonctionnelles.

Influence of heat treatments on the functional properties.

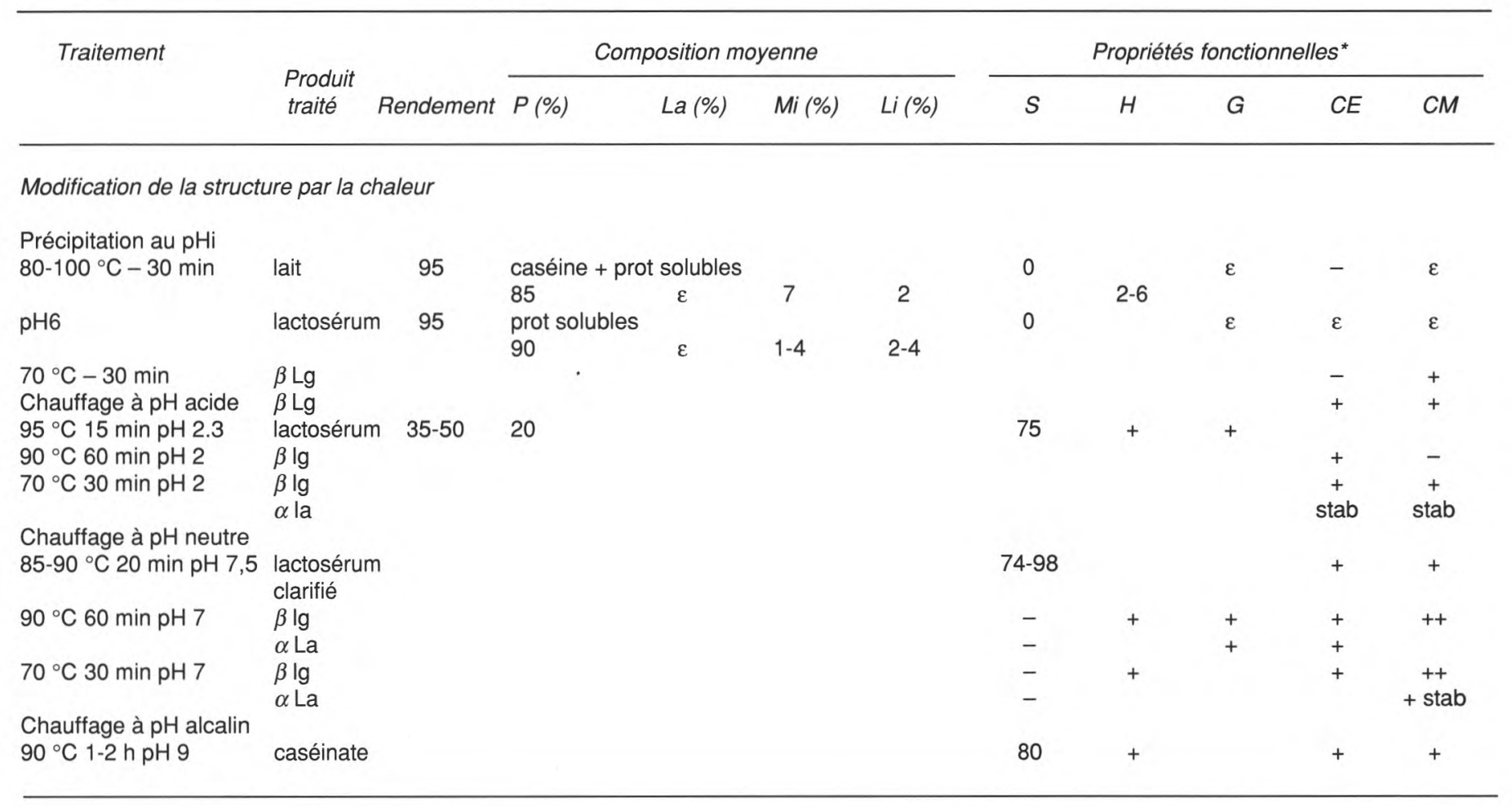

* Solubilité (\%); $\mathrm{H}=$ Hydratation $(\mathrm{ml} / \mathrm{g}) ; \mathrm{G}=$ Gélification; $\mathrm{CE}=$ Capacité émulsifiante (ml huile/g); $\mathrm{CM}=$ capacité moussante (\%).

* Solubility (\%): $H$ = hydration ( $\mathrm{ml} / \mathrm{g}$ ); $G$ = gelling; $C E$ = emulsifying capacity ( $\mathrm{ml} \mathrm{oil/g}$ ); $C M$ : foaming capacity (\%). 


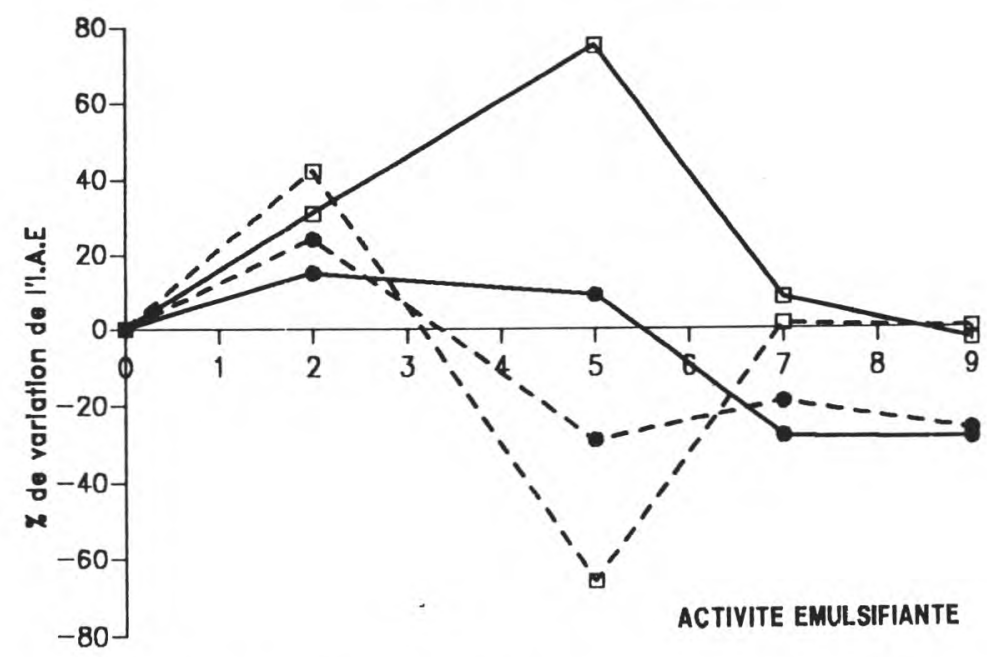

\begin{tabular}{|c|c|c|c|}
\hline$-a-$ Lactalbumine & $\rightarrow-a-$ Lactalbumine & + B-Lactoglobuline & $\bullet-$ B-Lactoglobuline \\
$70 \mathrm{C}-30 \mathrm{~min}$ & $90 \mathrm{C}-60 \mathrm{~min}$ & $70 \mathrm{C}-30 \mathrm{~min}$ & $90 \mathrm{C}-60 \mathrm{~min}$ \\
\hline
\end{tabular}

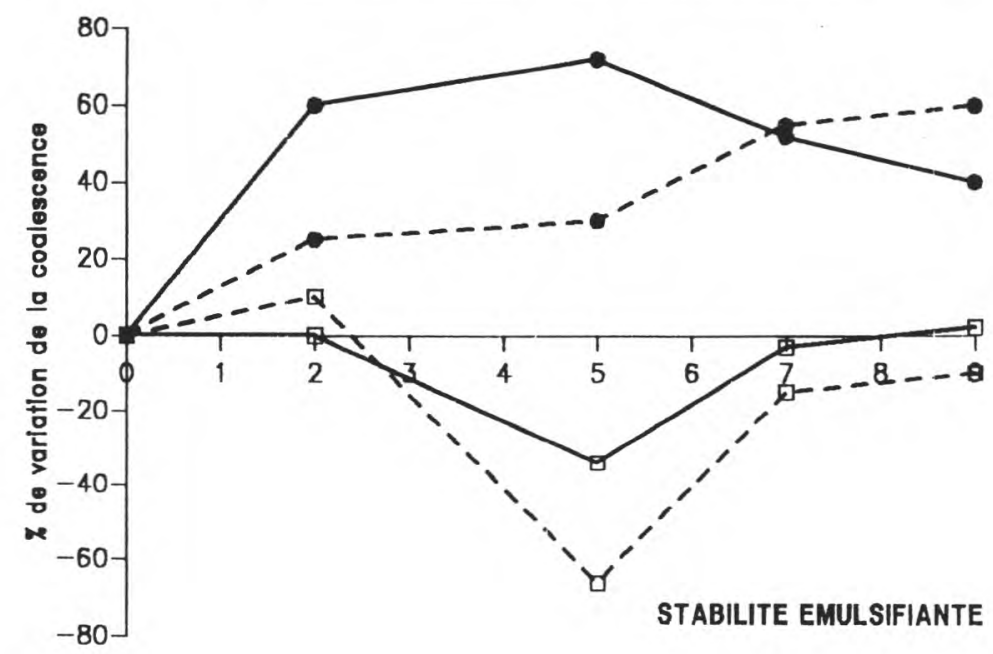

Fig 15. Influence des traitements thermiques effectués à différents $\mathrm{pH}$ sur l'activité émulsifiante (a) et la stabilité émulsifiante (b) mesurées à $\mathrm{pH}$ 7. Concentration protéique : $1 \mathrm{~g} . \mathrm{l}^{-1}$.

Influence of heat treatments carried out at different pHs on the emulsifying activity (a) and stability (b) of whey protein solutions ( $\mathrm{pH}$ 7; protein concentration : $1 \mathrm{~g} . \mathrm{H}^{-1}$.

dification discrète de structure; les études suivantes ont donc porté sur des conditions thermiques permettant une destructu- ration sans hydrolyse $\left(70^{\circ} \mathrm{C}-30 \mathrm{~min}\right.$, $\left.90^{\circ} \mathrm{C}-60 \mathrm{~min}\right)$ à $\mathrm{pH}$ peu acide, neutre et alcalin. 


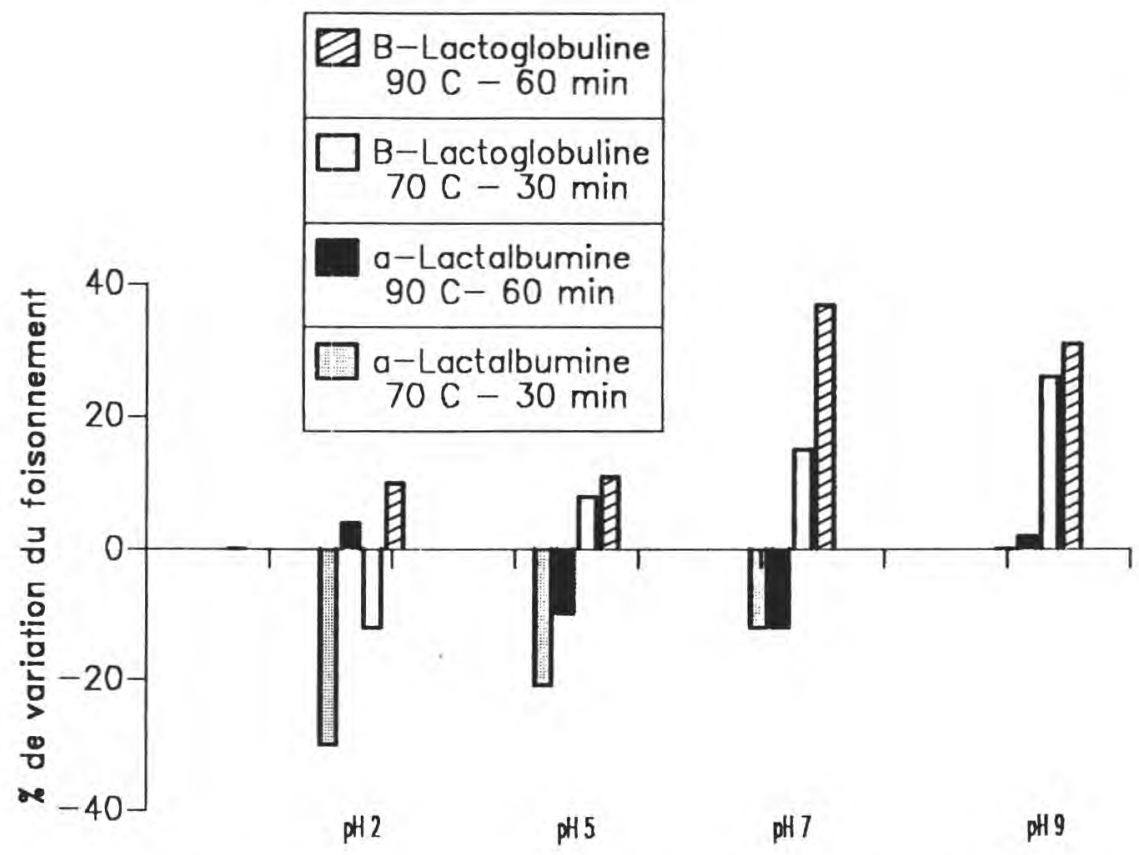

Fig 16. Foisonnement des protéines sériques après chauffage à différents $\mathrm{pH}$. Concentration protéique : $1 \mathrm{~g} . \mathrm{I}^{-1}$.

Overrun of whey protein solutions after heat treatment at different $\mathrm{pHs}(\mathrm{pH}$; ; protein concentration: 1 g..$\left.^{-1}\right)$.

\section{Propriétés émulsifiantes}

$\mathrm{A} 70{ }^{\circ} \mathrm{C}, 30 \mathrm{~min}$ et à $\mathrm{pH}$ acide ou proche du $\mathrm{pHi}$, les 2 protéines présentent une activité émulsifiante accrue, celle de la $\beta$-lactoglobuline étant toujours supérieure. À $90^{\circ} \mathrm{C}-60 \mathrm{~min}$, l'activité émulsifiante est seulement améliorée à $\mathrm{pH}$ acide. La stabilité des émulsions n'est augmentée par le chauffage, quel que soit le $\mathrm{pH}$, que dans le cas de l' $\alpha$-lactalbumine. La $\beta$-lactoglobuline étant fortement insolubilisée à pH 5 perd une partie de sa stabilité émulsifiante.

\section{Propriétés moussantes}

Pour la capacité moussante, les effets conjugués du $\mathrm{pH}$ et des traitements ther- miques paraissent opposés pour les 2 protéines : effet améliorant des chauffages à $\mathrm{pHi}$, neutre et alcalin pour la $\beta$ lactoglobuline, effet négatif pour l' $\alpha$ lactalbumine (surtout à $\mathrm{pH} 2$ ). Au contraire, la stabilité est surtout améliorée pour l' $\alpha$ lactalbumine surtout à $\mathrm{pH} 2$ et 5 .

Une explication complète de ces effets paraît difficile car elle doit prendre en compte une baisse de solubilité des protéines qui accompagne les taux élevés de dénaturation ainsi que l'effet des sels rencontrés dans les lactosérums. Ces résultats ont surtout le mérite de pouvoir prévoir le rôle respectif de chaque protéine et de sa proportion dans le concentré sans bien sûr prendre en compte l'effet des interactions. 


\section{Traitements chimiques}

La coupure des ponts disulfure par réduction permet de «modéliser" la dénaturation et le déplissement plus ou moins total des molécules. lung (1988) et Closs (1990) ont montré respectivement pour la $\beta$ lactoglobuline et l' $\alpha$-lactalbumine que la réduction accroît l'efficacité tensioactive et moussante. Kella et al (1989) précisent toutefois que les molécules sériques, présentant $75 \%$ des ponts disulfure réduits, possèdent les meilleures propriétés moussantes. L'existence d'un rapport optimal structure ordonnée/structure désordonnée a déjà été signalé par Song et Damodaran (1987).

Les modifications chimiques portant sur les chaînes latérales des protéines ont été très étudiées et de nombreuses revues ont été publiées (Cheftel et al, 1985; Chobert et Mesnier, 1988).

À l'heure actuelle, elles ne sont utilisées que pour confectionner des modèles afin de comprendre les relations structurefonction. Aucune application industrielle n'a été envisagée en raison du manque d'informations sur la toxicité des protéines modifiées. La phosphorylation chimique et la glycosylation par alkylation réductrice accroissent considérablement la solubilité ainsi que la viscosité et les activités émulsifiantes et moussantes des caséinates (Chobert et Mesnier, 1988; Courthaudon et al, 1989; Lorient et al, 1989),

Des modifications des chaînes latérales par voie enzymatique semblent plus intéressantes; la déphosphorylation des caséines par les phosphatases et la désamidation des résidus Gln et Asn modifient la polarité, la solubilité et les propriétés de surface qui y sont associées.

La transglutaminase conduit quant à elle, à une réticulation et une polymérisation, et par conséquent, à des modifications de propriétés rhéologiques : gélifica- tion des solutions de caséine $\alpha_{\mathrm{s} 1}$ et des émulsions qu'elles forment avec l'huile de soja (Nio et al, 1986).

\section{Modification par réduction de la taille}

Bien qu'un traitement thermique très limité à $\mathrm{pH} 2$ puisse améliorer les propriétés de surface de la $\beta$-lactoglobuline par désamidation ou hydrolyse (lung, 1988), la réduction de la taille moléculaire est en général obtenue par protéolyse. Une revue récente de cet aspect a été publiée par lung et Linden (1988).

Une protéolyse limitée des protéines de lactosérum non dénaturées a peu d'effet sur les capacités émulsifiantes et moussantes; la stabilité des émulsions et des mousses est même souvent altérée. II semble que les effets positifs observés par certains auteurs (lung, 1988; Chobert et al, 1988) aient été obtenus sur des concentrés protéiques de lactosérum en poudre donc déjà dénaturés voire polymérisés; dans ce cas, comme dans celui des grosses molécules (globulines de légumineuses), une dépolymérisation est nécessaire pour accroître les propriétés tensioactives et la solubilité.

En ce qui concerne les caséines, Shimizu et al (1986) ainsi que Wilson et al (1989) montrent qu'une protéolyse libère des peptides tensioactifs (par exemple le fragment $1-23$ de la caséine $\alpha_{s 1}$ et caséines $\gamma$ et protéose-peptones libérées de la caséine $\beta$ par la plasmine respectivement) mais n'ayant aucun rôle stabilisant des interfaces; cependant, on soupçonne certains de ces peptides d'être contaminés par d'autres peptides tensioactifs!

\section{Procédés de texturation}

Les traitements de texturation en continu se sont beaucoup développés en vue de 
confectionner des fromages fondus, des analogues de fromage ou des structures foisonnées à teneur variable en matière grasse. Les 2 principaux procédés étudiés sont surtout :

- la cuisson extrusion utilisant l'appareillage comme un réacteur en continu et permettant la confection à partir de caséine et de protéines de lactosérum, des gels hydratés émulsifiés ou des analogues de matière grasse (Queguiner et al, 1990);

- le foisonnement en continu de mix protéiques contenant des proportions variées de matière grasse. Les meilleurs résultats semblent obtenus par des échangeurs à surface raclée qui permettent d'associer l'agitation en continu à un chauffage modéré (Poma et al, 1989).

\section{CONCLUSION}

Les progrès récents réalisés dans la purification des protéines, dans la maîtrise de la composition des concentrés protéiques et dans la conduite des procédés d'amélioration, permettent d'envisager l'utilisation en mélange de nombreuses protéines d'origine diverse (laitière, carnée, végétale, etc), le choix se faisant alors en fonction des propriétés spécifiques de celles-ci pour des usages précis à condition bien sûr que les chercheurs aient pu maîtriser la compatibilité des ingrédients entre eux.

\section{RÉFÉRENCES}

Anderson M, Brooker BE (1988) A model system for studying protein binding to hydrophobic surfaces in emulsion. Dairy foams. In: $A d$ vances in Food Emulsion and Foams (Dickinson E, Stainsby G, eds) Elsevier Applied Science, London and New York, 221255

Anderson M, Brooker BE, Needs EC (1987) The role of proteins in the stabilization/ destabilization of dairy foams. In: Food Emulsions and Foams (Dickinson E, ed) Royal Soc Chem, Londres, 100-109

Blond G, Le Meste M (1988) Propriétés d'hydratation des macromolécules. Relation avec des propriétés fonctionnelles. In: Propriétés fonctionnelles des macromolécules alimentaires, Les Cahiers de I'ENS.BANA (Lorient D, Colas B, Le Meste M, eds) Lavoisier Tec et Doc, Paris, 11-32

Brock CJ, Enser M (1987) A model system for studying protein binding to hydrophobic surfaces in emulsions. J Sci Food Agric 40, 263273

Cayot P (1989) Étude des propriétés de surface des constituants $\alpha_{s 1}$ et $\beta$ de la caséine bovine, purs et en mélange. DEA Sciences des Aliments. ENS.BANA, Dijon

Cayot $P$, Courthaudon $\mathrm{JL}$, Lorient $\mathrm{D}$ Emulsifying properties of $\alpha_{\mathrm{s} 1}$ and $\beta$ caseins in pure or mixed solutions. I Agric Food Chem (Submitted)

Cheftel JC, Lorient D (1982) Les propriétés fonctionnelles des protéines laitières et leur amélioration. Lait 62, 435-483

Cheftel JC, Cuq JL, Lorient D (1985) Protéines alimentaires. Lavoisier Tec et Doc, Paris

Cherry JP (1982) Protein-polysaccharide interactions. In: Food Carbohydrates (Lineback DR, Inglett FE, eds) AVI Publ Co, 375-398

Chobert JM, Mesnier D (1988) Procédés chimiques d'amélioration des propriétés fonctionnelles. In: Propriétés fonctionnelles des macromolécules alimentaires, Les Cahiers de I'ENS, BANA (Lorient D, Colas B et Le Meste M, eds) Lavoisier Tec et Doc, Paris, 175-198

Chobert JM, Bertrand-Harb C, Nicolas MG (1988) Solubility and emulsifying properties of caseins and whey proteins modified enzymatically by trypsin. J Agric Food Chem 36 , 883-892

Closs B (1990) Influence de la structure sur les propriétés de surface des protéines de lactosérum. Thèse de Doctorat, Univ Bourgogne, ENS.BANA, Dijon

Closs B, Courthaudon JL, Lorient D (1990) Effect of chemical glycosylation on the surface properties of the soluble fraction of casein. $J$ Food Sci 55, 437-439

Colas B (1988) Viscosité des caséines, caséinates et coprécipités. In: Propriétés fonction- 
nelles des macromolécules alimentaires, Les Cahiers de I'ENS.BANA (Lorient D, Colas B, Le Meste $M$, eds), Lavoisier Tec et Doc Paris, 89-103

Colas B, Courthaudon JL, Le Meste M, Simatos D (1988) Functional properties of caseinates: the role of the flexibility of the protein and of its hydration level on surface properties. In: Proceedings of International Seminar on Functional Properties of Food Proteins. Budapest, Septembre 7-9 (Lasztity R, ed) 186194

Courthaudon JL (1990) Étude des propriétés techno-fonctionnelles de la caséine bovine : incidence de la glycosylation chimique. Thèse de doctorat, Université de Bourgogne, ENS.BANA, Dijon

Courthaudon JL, Colas B, Lorient D (1989) Covalent binding of glycosyl residues to bovine casein: effects on solubility and viscosity. $J$ Agric Food Chem 37, 32-36

De Wit JN (1984) Functional properties of whey proteins in food systems. Neth Milk Dairy $J$ $38,71-89$

De Wit JN, Klarenbeck G (1984) Effects of various heat treatments on structure and solubility of whey proteins. J Dairy Sci 67, 27012710

De Wit JN, Hontelez-Backx E, Adamse M (1988) Evaluation of functional properties of whey protein isolate. 3 . Functional properties in aqueous solutions. Neth Milk Dairy $J$ 42, 155-172

Dickinson E (1986) Mixed protein aqueous emulsifiers: review of competitive protein adsorption and the relationship to food colloid stabilization. Food Hydrocolloids 1, 3-23

Dickinson E (1989) Surface and emulsifying properties of caseins. J Dairy Res 56, 471-477

Dickinson E, Rolfe SE, Dalgleish DG (1988) Competitive adsorption of $\alpha_{S T^{-}}$-casein and bcasein in oil-in-water emulsions. Food Hydrocolloids 2, 397-405

Dickinson E, Rolfe SE, Dalgleish DG (1989a) Competitive adsorption in oil-in-water emulsions containing $\alpha$-lactalbumin and $\beta$ lactoglobulin. Food Hydrocolloids 3, 193-203

Dickinson E, Narhan SK, Stainsby G (1989b) Stability of cream liqueurs containing lowmolecular-weight surfactants. J Food Sci 54 , $77-81$
Dickinson E, Euston SR, Woskett CM (1990) Competitive adsorption of food macromolecules and surfactants at the oil-water interface. Prog Colloid Polym Sci 82 (in press)

Dumay $E$ (1988) Dénaturation thermique de la $\beta$-lactoglobuline et propriétés gélifiantes des concentrés protéiques de lactosérum. In: Propriétés fonctionnelles des macromolécules alimentaires, Les Cahiers de I'ENS.BANA (Lorient D, Colas B, Le Meste M, eds) Lavoisier Tec et Doc, Paris, 67-87

Fox PF, Mulvihill DM (1983) Functional properties of casein, caseinates and coprecipitates. In: Proc Int Dairy Fed Symp Physico-Chemical Aspects of Dehydrated Protein. Rich Milk Products, Helsingor, Denmark, 188-285

Goff HD, Jordan WK (1989) Action of emulsifiers in promoting fat destabilization during the manufacture of ice-cream. J Dairy Sci 72, 18-29

Goff HD, Kinsella JE, Jordan WK (1989) Influence of various milk protein isolates on ice-cream stability. J Dairy Sci 72, 385-397

Haque Z, Kristjansson MH, Kinsella JE (1987) Interaction between $\kappa$-casein and $\beta$ lactoglobulin: possible mechanism, I Agric Food Chem 35, 644-649

lung C (1988) Les propriétés fonctionnelles des protéines du lactosérum. Étude modélisée avec la $\beta$-lactoglobuline. Thèse de doctorat, université de Nancy

lung C, Linden G (1988) Procédés enzymatiques d'amélioration des propriétés fonctionnelles des macromolécules alimentaires. In: Propriétés fonctionnelles des macromolé. cules alimentaires, Les Cahiers de I'ENS.BANA (Lorient D, Colas B et Le Meste M, eds) Lavoisier Tec et Doc, Paris, 199-224

Jang HD, Swaisgood HE (1989) Disulfide bond formation between thermally denatured $\beta$ lactoglobulin and $\kappa$-casein in casein micelles. J Dairy Sci 73, 900-904

Kaivarainen Al (1985) Solvent Dependant Flexibility of Proteins and Principles of their Function. Reidel Publ Co, Londres

Kalab M, Emmons DB (1972) Heat induced milk gels. V. Some chemical factors influencing the firmness. J Dairy Sci 55, 1225-1230

Kato A, Matsuda T, Matsudomi N, Kobayashi K (1984) Determination of protein hydrophobici- 
ty using a sodium dodecyl sulfate binding method. J Agric Food Chem 32, 284-287

Kella NKD, Jang ST, Kinsella JE (1989) Effect of disulfide bond cleavage on structural and interfacial properties of whey proteins. J Agric Food Chem 37, 1203-1209

Kinsella JE (1984) Milk proteins: physicochemical and functional properties. CRC Crit Rev Food Sci Nutr 23, 197-262

Kinsella JE, Fox PF (1985) Water sorption by proteins: milk and whey proteins. CRC Crit Rev Food Sci Nutr 24, 91-139

Laliberté MF, Britten M, Paquin P (1988) Interfacial properties of sodium caseinate/ monoglyceride mixture; combined effects of $\mathrm{pH}$ and surface area ratios. Can Inst Food Sci Technol J 21, 251-254

Ledward DA (1978) Protein-polysaccharides interactions, In: Polysaccharide in Foods (Lanshard JMVB and Mitchel JR, eds) Butterworths, Boston, 205-217

Lee HS, Shimizu M, Kaminogawa S, Yamauchi K (1987) Emulsifying properties of peptides obtained from the hydrolysates of $\beta$-casein. Agric Biol Chem 56, 161-166

Leman J, Kinsella JE (1989) Surface activity film formation and emulsifying properties of milk proteins. CRC Crit Rev Food Sci Nutr 28, $115-136$

Le Meste M, Colas B, Simatos D, Closs B, Courthaudon JL, Lorient D (1990) Contribution of protein flexibility to the interfacial behavior of caseins. J Food Sci (in press)

Lorient D, Linden G (1990) Fractionnement des protéines du lait par utilisation d'échangeurs d'ions en «batch». 4th Symp Prot Purif Technol. Clermont Ferrand. 14-16 mars

Lorient D, Closs B, Courthaudon JL (1989) Surface properties of the bovine casein components: relationships between structure and foaming properties. J Dairy Res 56, 495-502

Maubois JL, Léonil J (1989) Peptides du lait à activité biologique. Lait 69, 245-269

Modler HW (1985) Functional properties of non fat dairy ingredients - a review. Modifications of products containing casein. J Dairy Sci68, 2195-2205

Mottar J, Bassier A, Joniau M, Baert J (1989) Effect of heat induced association of whey proteins and casein micelles on yogurt texture. J Dairy Sci 72, 2247-2256
Nakai S (1983) Structure-function relationships of food proteins with an emphasis on the importance of protein hydrophobicity. I Agric Food Chem 31, 676-683

Nio N, Motoki MP, Takinami K (1986) Gelation of protein emulsion by transglutaminase. Agric Biol Chem 50, 1409-1412

Noh B, Richardson T (1989) Incorporates of radiolabeled whey proteins into casein micelles by heat processing. J Dairy Sci 72, 1724 1731

Paulsson M, Dejmek P (1990) Thermal denaturation of whey proteins in mixture with caseins studied by differential scanning calorimetry. J Dairy Sci 73, 590-600

Payens TA (1982) Les propriétés physicochimiques des caséines $\alpha_{s}, \beta$ et $\kappa$. Lait 62 , 306-320

Poma JP, Gonzalez N, Duprat JC, Touron B (1989) La production en continu de produits foisonnés. Ind Alim Agric 106, 1015-1020

Queguiner C, Dumay E, Salou-Cavalier C, Cheftel JC (1990) Modification and texturization of milk protein by extrusion. Cooking Symp on extrusion and rheology of foods. 31st July3rd August Univ Rutgers, New Jersey, USA

Relkin P, Launay B (1990) Concentration effects on the kinetics of $\beta$-lactoglobulin heat denaturation: a differential scanning calorimetry study. Food Hydrocolloids 4, 19-32

Robson WE, Dalgleish DG (1987) Interfacial composition of sodium caseinate emulsions. J Food Sci 52, 1694-1698

Schmitt S (1990) Étude des propriétés moussantes et du comportement interfacial des fractions $\alpha_{s 1}, \beta$ et $\kappa$ de la caséine bovine, pure et en mélange. DEA sciences des aliments, ENS.BANA, Dijon

Shimada K, Cheftel JC (1988) Texture characteristics, protein solubility and sulfhydryl group, disulfide bond contents of heat induced gels of whey protein isolate. J Agric Food Chem 36, 1018-1025

Shimizu M, Takahashi T, Kaminogawa S, Yamauchi K (1983) Adsorption onto an oil surface and emulsifying properties of bovine $\alpha_{\mathrm{s} 1}$-casein in relation to its molecular structure. J Agric Food Chem 31, 1214-1218

Shimizu M, Saito M, Yamauchi K (1986) Hydrophobicity and emulsifying activity of milk proteins. Agric Biol Chem 50, 791-792 
Song KB, Damodaran S (1987) Structure function relationship of proteins: adsorption of structural intermediates of bovine serum albumin at the air-water interface. J Agric Food Chem 35, 236-241

Townsend A, Nakai S (1983) Relationships between hydrophobicity and foaming characteristics of food proteins. J Food Sci 48, 588594

Varunsatian S, Watanabe K, Hayakawa S, Nakamura R (1983) Effects of $\mathrm{Ca}^{2+}, \mathrm{Mg}^{2+}$ and
$\mathrm{Na}^{+}$on heat aggregation of protein concentrate. J Food Sci 48, 42-46, 70

Wilson M, Mulvihill DM, Donnelly WJ, Gill BP (1989) Surface active properties at the airwater interface of $\beta$-casein and its fragments derived by plasmin proteolysis. J Dairy Res $56,487-494$

Woskett CM (1989) Competitive adsorption and protein surfactant interactions in food emulsions. Ph D Thesis, University of Leeds 